\title{
Geologia e aspectos petrológicos das rochas intrusivas e efusivas mesozóicas de parte da borda leste da bacia do Paraná no estado de São Paulo
}

\author{
Fábio Braz Machado ${ }^{1}$, Antonio José Ranalli Nardy ${ }^{2}$ \& Marcos Aurélio Farias de Oliveira ${ }^{3}$
}

\begin{abstract}
Resumo A borda leste da Bacia Paraná no Estado de São Paulo é caracterizada por um grande volume de rochas intrusivas, principalmente sills de diabásio, associados à Província Magmática do Paraná (PMP), encaixados preferencialmente na porção superior do Supergrupo Tubarão, bem como nos calcários e lamitos das Formações Irati e Corumbataí. A investigação petrográfica destas rochas intrusivas e dos derrames próximos, mostrou que são constituídas essencialmente por plagioclásio, piroxênios (augita e pigeonita), minerais opacos e mesóstase (vítrea e/ou microgranular), caracterizando texturas predominantemente intergranular, subofítica e ofítica. Dados geoquímicos de elementos maiores, menores, traços e ETR indicaram que essas rochas são de natureza básica e caráter toleítico do tipo alto-titânio $\left(\mathrm{TiO}_{2} \geq 2 \%\right)$. Essas diferenças geoquímicas também indicam três magmas distintos (subgrupos)- Urubici, Pitanga e Paranapanema, que se distribuem de forma localizada pela área investigada. As do tipo Paranapanema $\left(1,7 \%<\mathrm{TiO}_{2}<3,2 \% ; 200 \mathrm{ppm}<\mathrm{Sr}<450 \mathrm{ppm}\right)$ estão concentradas na região de Campinas, próxima ao embasamento cristalino; as do tipo Pitanga $\left(\mathrm{TiO}_{2} \%>2,9\right.$ e $\mathrm{Sr}>350 \mathrm{ppm}$ ) na maioria das intrusivas e derrames próximos (regiões de Jaú e Franca), enquanto as do tipo Urubici ( $\mathrm{TiO}_{2} \%>3,3$ e $\mathrm{Sr}>550 \mathrm{ppm}$ ) estão distribuídas entre os sills da região de São Sebastião do Paraíso, em Minas Gerais, e os derrames no nordeste do Estado de São Paulo. Sendo assim, o estudo na área investigada, mostrou que as rochas intrusivas e derrames podem apresentar gênese e processos de evolução magmática distintos.
\end{abstract}

Palavras-chave: Província Magmática do Paraná; Formação Serra Geral; Bacia do Paraná; Rochas Intrusivas.

\begin{abstract}
Geology and petrographic aspects of the intrusive and extrusive mesozoic rocks of the eastern portion of the Paraná Basin, São Paulo State. The eastern edge of the Paraná Basin in the State of São Paulo, shows a great number of sills and dikes, of basaltic composition, related to the Paraná Magmatic Province (PMP), intruded mainly in the upper portion of the Tubarão Group, and also in the Irati and Corumbataí Formations. Petrographic analyzes of intrusive rocks and also of the lava flows indicated that they are constituted essentially by plagioclase, pyroxenes (augite and pigeonite), magnetite and mesostase (glass and/or microgranular), characterizing predominantly intergranular, subofític and ofític textures. On the other hand, the geochemical analyzes indicate that the rocks present basic nature, toleiitic affinity and can be classified in the group of high titanium (HTi) of the PMP. Moreover, the geochemical characteristics also indicate three distinct type of magmas (Urubici, Pitanga and Paranapanema), with a distinct occurrence for each one. Those of the Paranapanema type $\left(1,7 \%<\mathrm{TiO}_{2}<3,2 \% ; 200 \mathrm{ppm}<\mathrm{Sr}<450 \mathrm{ppm}\right)$ are concentrated in the region of Campinas, next to the crystalline basement; the Pitanga type $\left(\mathrm{TiO}_{2}>2,9 \%<\right.$; $\left.\mathrm{Sr}>350 \mathrm{ppm}\right)$ represent the majority of the intrusive bodies and lava flows (region of Jaú and Franca), while the Urubici type $\left(\mathrm{TiO}_{2}>3,3 \%<; \mathrm{Sr}>550 \mathrm{ppm}\right)$ is intrusive in the region of São Sebastião do Paraíso, Minas Gerais States, and lava flows of the northeast of the São Paulo State. Thus, in the investigated area, distinct processes of magmatic evolution are involved for the intrusives and extrusive basaltic rocks.
\end{abstract}

Keywords: Magmatic Province of the Paraná; Serra Geral Formation; Paraná Basin; Intrusive Rocks.

INTRODUÇ̃̃o A Província Magmática do Paraná (PMP) é considerada como umas das maiores manifestações vulcânicas de caráter básico em área continental, na forma de derrames e rochas intrusivas (sills e diques).

De fato, o volume de lava recobre grande parte do sul e sudeste do Brasil, envolvendo os estados do Rio Grande do Sul, Paraná, Santa Catarina, São Paulo, sudoeste de Minas Gerais, sudeste do Mato Grosso do
Sul, sul de Goiás, e leste do Mato Grosso, além da parte ocidental do Uruguai, nordeste da Argentina e extremo leste do Paraguai, como mostra o mapa da figura 1.

Embora o volume de informações referentes aos derrames seja relativamente abundante, ainda pouco se conhece sobre a natureza geoquímica das rochas intrusivas que compõem a PMP principalmente no que concerne às suas relações estratigráficas e petrogenéticas. 


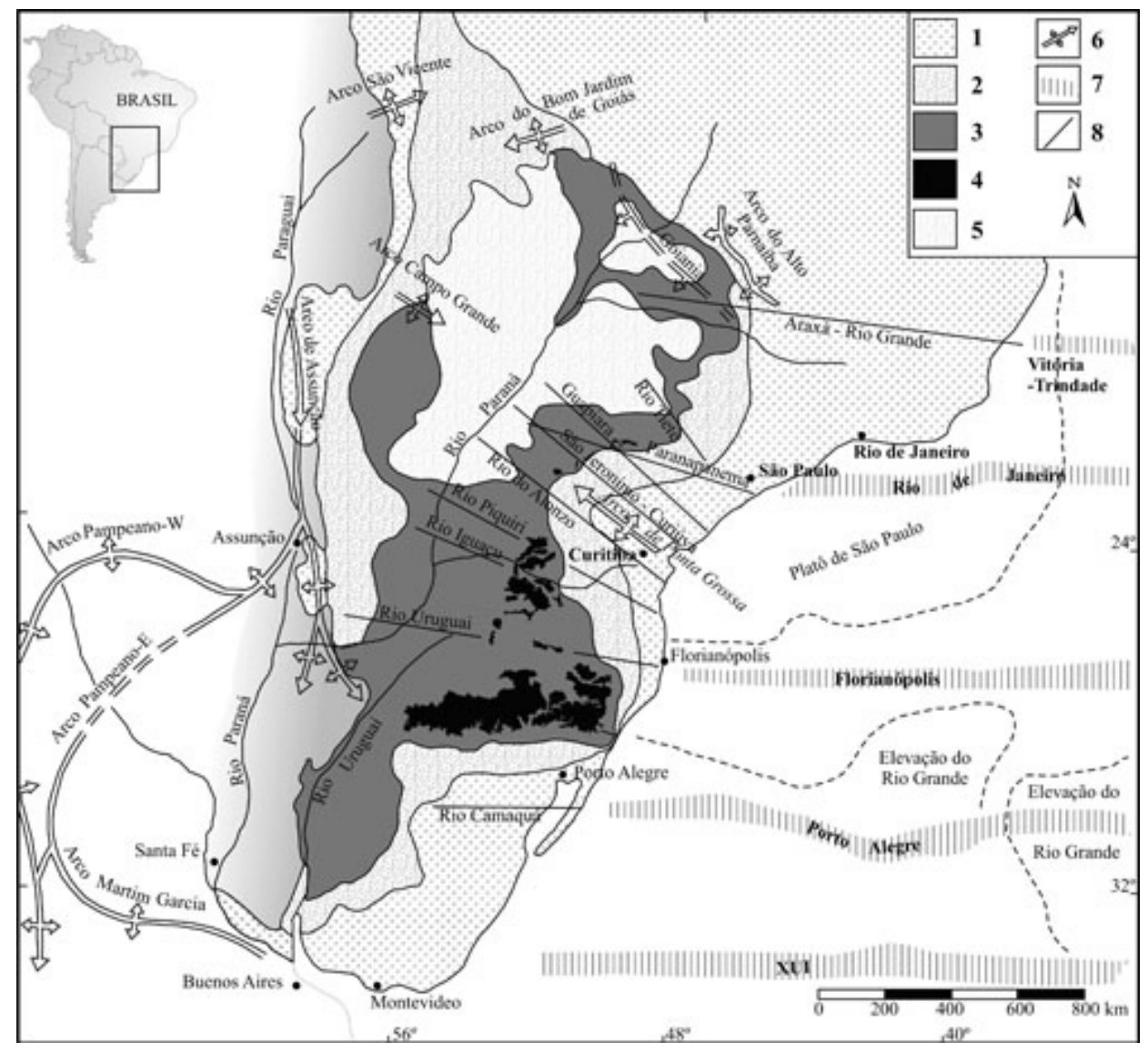

Figura 1-Mapa Geológico simplificado da Bacia do Paraná mostrando os principais elementos geotectônicos presentes. Segundo Asmus \& Baisch (1983) e Milani (2004), com disposição dos platôs de rochas ácidas segundo Nardy et al. (2002). Legenda: 1 - Embasamento cristalino adjacente; 2 - Sedimentos pré-vulcânicos; 3 - Derrames da Formação Serra Geral; 4 - Rochas ácidas da Formação Serra Geral; 5 - Sedimentos pós-vulcânicos; 6 - Estrutura anticlinal; 7 - Lineamentos Oceânicos; 8 - Lineamento tectônico elou magnético.

Buscando preencher esta lacuna de conhecimento acerca dessas rochas intrusivas, uma área na porção centro-leste do Estado de São Paulo foi escolhida para uma coleta sistemática de amostras de sills, diques e derrames percorrendo as rodovias principais disponíveis na região. As pesquisas em andamento, na área objeto deste estudo mostram diferenças geoquímicas entre os basaltos e diabásios inéditos na literatura.

Com estas novas informações espera-se contribuir para um melhor entendimento do contexto petrogenético e geodinâmico no qual se insere a Província Magmática do Paraná.

\section{A PROVÍNCIA MAgMÁtiCA DO PARANÁ} (PMP) Os derrames associados à PMP estão dispostos sobretudo na porção sudeste do continente sul-americano, e desenvolveram-se não só sobre a bacia sedimentar do Paraná, onde constituem a Formação Serra Geral do Grupo São Bento, mas também nas áreas adjacentes a bacia, envolvendo o embasamento cristalino e as bacias marginais no Oceano Atlântico.

Os pacotes de lavas assentam-se sobre os arenitos da Formação Botucatu em contato concordante e abrupto, gerando muitas vezes intertraps, cuja origem parece estar relacionada a uma pausa no evento vulcânico, ou até mesmo na penetração do magma, na forma de sills, nos sedimentos pré-vulcânicos. Cabe ressaltar que, na parte norte da bacia, os derrames assentam-se diretamente sobre o embasamento cristalino, enquanto que na parte sul, na ausência do Arenito Botucatu, sobre os sedimentos lacustres e triássicos da Formação Santa Maria, Assine et al. (2004).

O complexo vulcânico remanescente recobre $75 \%$ de toda a Bacia do Paraná, como mostra a figura 1 , com volume estimado em $780.000 \mathrm{~km}^{3}$ dispostos em 1.200.000 $\mathrm{km}^{2}$. Embora estes valores permitam considerar a PMP como uma das maiores manifestações de vulcanismo continental observada no planeta, segundo Gallagher et al. (1994) eles seriam, bem menores do que aqueles iniciais. Segundo Almeida (1986) a espessura média dos derrames da Formação Serra Geral é próximo a $650 \mathrm{~m}$, com possível depocentro localizado na região de Cuiabá Paulista, na porção sudoeste do Estado de São Paulo, aonde as espessuras dos pacotes vulcânicos chegam até $1700 \mathrm{~m}$. 
Datações do tipo ${ }^{40} \mathrm{Ar} /{ }^{39} \mathrm{Ar}$, de alta precisão, e dados paleomagnéticos, indicam que atividade vulcânica que deu origem aos derrames da Formação Serra Geral ocorreu principalmente entre 133 e $132 \mathrm{Ma}$, sendo que as rochas mais jovens se encontram na porção norte da província, enquanto as mais antigas na porção sul segundo Renne et al. (1992) e Ernesto et al. (1999), indicando evolução da atividade vulcânica se deu de sul para norte.

Além da extensa área de derrames, deve-se também destacar as várias ocorrências de rochas intrusivas ligadas ao vulcanismo Serra Geral, cuja área de afloramento se estende praticamente por todos os limites da província, sendo que, os afloramentos mais extensos estão localizados na porção centro-leste do Estado de São Paulo. Ainda, a grande área de exposição na porção oriental da bacia parece ter sido afetada por forte denudação ocorrida devido à reativação de alinhamentos estruturais, em especial aqueles de direção NW-SE, conforme comprovam os dados termocronológicos de Godoy (2006).

Caracterização e compartimentação litológica e geoquímica da PMP A Província Magmática do Paraná é caracterizada predominantemente pelos derrames da Formação Serra Geral que são caracterizados predominantemente por basaltos e subordinadamente por andesitos (cerca de $7 \%$ do volume total), e riodacitos e riolitos (cerca de 2,5\% do total) segundo Bellieni et al. (1986b), Piccirillo et al. (1988) e Nardy et al. (2002). Os basaltos apresentam caráter toleítico e podem ser divididos em dois grupos distintos denominados de alto (ATi, $\mathrm{TiO}_{2} \geq 2 \%$ ) e baixo titânio $\left(\mathrm{BTi}, \mathrm{TiO}_{2}<2 \%\right.$ ) e que, a grosso modo, distribuem-se pelas regiões norte (ao norte do alinhamento do Rio Piquiri) e sul (ao sul do Alinhamento do Rio Uruguai) da província respectivamente, Bellieni et al. (1983, 1984a b, 1986a b), Mantovani et al. (1985), Piccirillo \& Melfi (1988), Piccirillo et al. (1987, 1989) e Marques et al. (1989), figura 2.

O acúmulo de informações de elementos maiores, menores, traços e de geoquímica isotópica acerca destas rochas, permitiu ainda a divisão em seis tipos diferentes magmas (subgrupos) conforme o esquema apresentado na tabela 1, Peate et al. (1992). Além disso, a distribuição esquemática destes basaltos não se faz de maneira aleatória pela Província Magmática do Paraná, mas sim de forma localizada conforme mostra a figura 2. É importante destacar que cálculos petrogenéticos conduzidos por Petrini et al. (1987) e Piccirillo et al. (1989), mostram que as suítes alta e baixa em titânio não possuem vínculo genético e, portanto caracterizam magmas distintos.

GEOLOGIA LOCAL A área investigada, localizada na borda leste da Bacia do Paraná no Estado de São Paulo, é composta por rochas sedimentares pertencentes ao Supergrupo Tubarão, pelas Formações Irati e Corumbataí do Grupo Passa Dois, e das Formações Pirambóia, Botucatu e Serra Geral do Grupo São Bento, além do embasamento cristalino adjacente à bacia, conforme

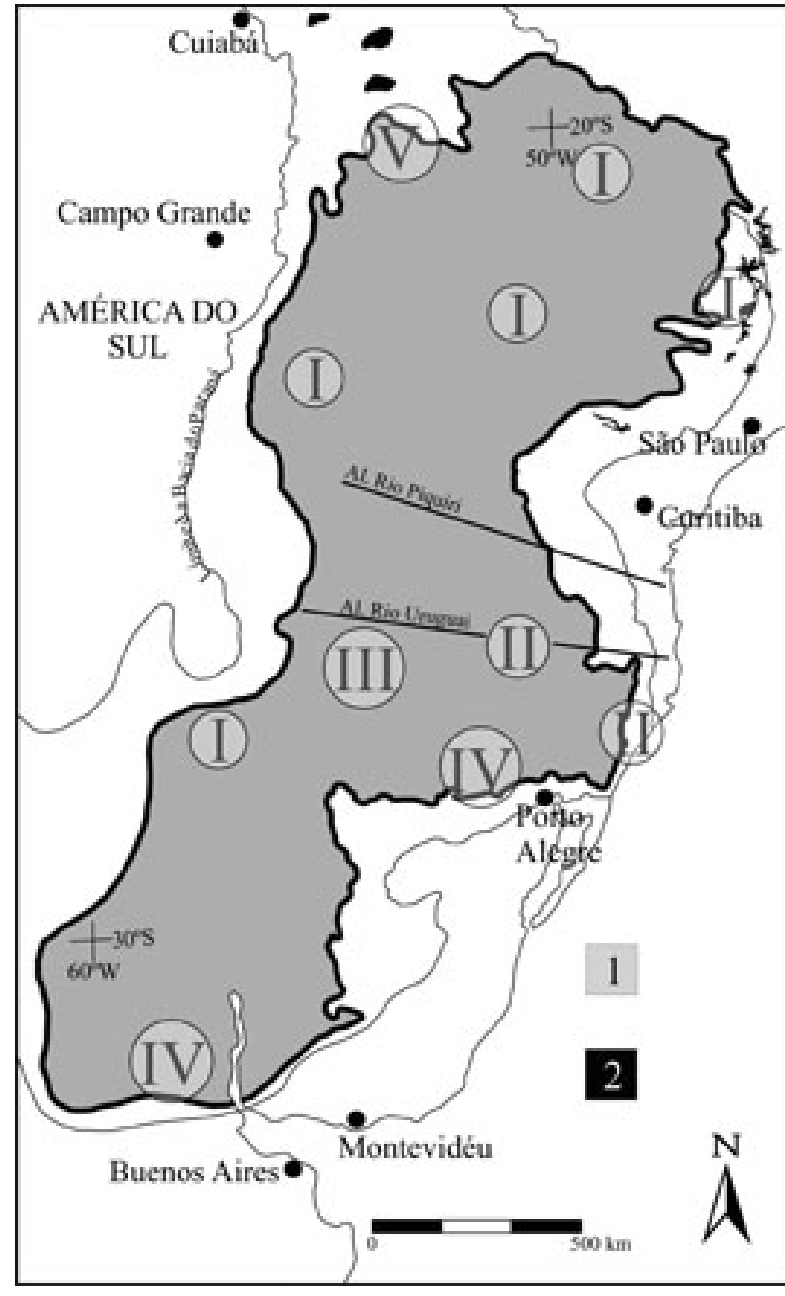

Figura 2 - Mapa esquemático indicando os locais de ocorrência do diferentes subgrupos de magmas básicos (I a IV) da Província Magmática do Paraná segundo informações contidas em Peate et al. (1992). Os tipos I e II são rochas do tipo ATi, enquanto III, IV e V são rochas BTi. Legenda: 1 Derrames; 2 -Sills; I-Paranapanema e Pitanga; II - Urubici; III - Esmeralda; IV - Gramado; V - Ribeira.

mostra o mapa geológico da figura 3.

A maior parte dos sills aflorantes na região é caracterizado por corpos tabulares de grande persistência lateral, estando encaixados nos siltitos, diamictitos e arenitos do Supergrupo Tubarão. Contudo, os corpos superficialmente mais extensos, estão localizados no intervalo estratigráfico que compreende as rochas mecanicamente menos resistentes, sendo elas as porções superiores do Supergrupo Tubarão (siltitos e diamictitos do Grupo Itararé e siltitos arenosos da Formação Tatuí), Formação Irati (principalmente os folhelhos do Membro Taquaral) e Formação Corumbataí (siltitos, argilitos e folhelhos). Além disso, também ocorrem, sills intrudidos nos arenitos síltico-argilosos da Formação Pirambóia, raramente chegando até a Formação Botucatu.

Também foi verificada a presença de xenólitos 


\section{Legenda}

Grupo Bauru

- Formação Serra Geral (derrames | intrusivas)

Sedimentos pré - vulcânicos

Ei Embasamento Cristalino

$\sim$ Drenagens principais

- Cidades

- Limite estadual (SP/MG)

- Local de coleta de amostras

Regiões de intrusivas investigadas
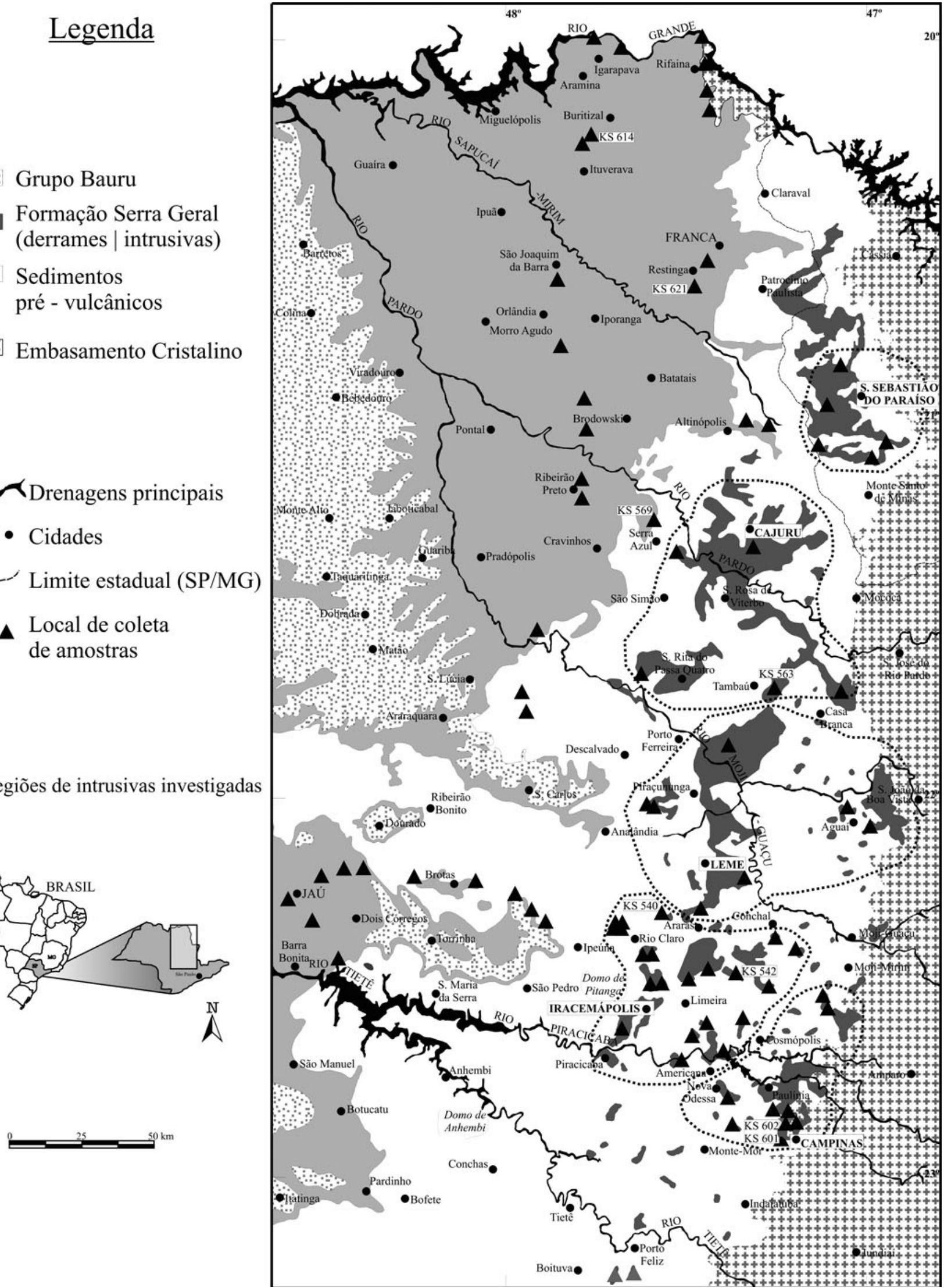

Figura 3 - Mapa Geológico simplificado de CPRM (2005), da área investigada, com disposição dos locais de coleta de amostras.

nos corpos magmáticos intrusivos gerados pelo fluxo do magma, onde grandes blocos de rocha encaixante são engolfados por este. Como exemplo, o sill aflorante próximo da cidade de Rio Claro, onde um grande bloco 
Tabela 1 - Características principais da composição química das diferentes lavas (subgrupos) de basaltos da Formação Serra Geral, segundo Peate et al. (1992).

\begin{tabular}{|c|c|c|c|c|c|}
\hline Subgrupos & $\mathrm{TiO} 2(\%)$ & $\mathrm{Sr}(\mathrm{ppm})$ & $\mathrm{Ti} / \mathrm{Y}$ & $\mathrm{Zr} / \mathrm{Y}$ & \\
\hline Urubici & $>3,3$ & $>550$ & $>500$ & $>6,5$ & \multirow{3}{*}{ ATi } \\
\hline Pitanga & $>2,9$ & $>350$ & $>350$ & $>5,5$ & \\
\hline Paranapanema & $1,7-3,2$ & $200-450$ & $>330$ & $4-7$ & \\
\hline Gramado & $0,75-1,9$ & $140-400$ & $<300$ & $3,5-6,5$ & \multirow{3}{*}{ BTi } \\
\hline Esmeralda & $1,1-2,3$ & $<250$ & $<330$ & $2-5$ & \\
\hline Ribeira & $1,5-2,3$ & $200-375$ & $<300$ & $3,5-7$ & \\
\hline
\end{tabular}

de calcário, pertencente à porção inferior da Formação Corumbataí, foi anexado ao corpo magmático, como mostra a foto da figura 4.

A região investigada também é caracterizada pela presença de diques, menos freqüentes que os sill, que ocorrem em grande número próximo aos dois principais domos da região, Pitanga e Anhembi (Fig. 3 ), onde a forte ocorrência de alinhamentos estruturais e falhas geológicas geradas próximas aos horts e domos, parecem ter exercido certo controle na intrusão do magma durante o Eocretáceo que, em grande maioria, devido a pequena espessura, possuem graus diferentes de intemperização, dificultando desta forma a coleta de amostras e conseqüente levantamento de dados geoquímicos.

Observou-se também em afloramento próximo à cidade de Rio Claro (SP), a presença de diques intrudidos em sills de diabásio, como mostra a figura 5, o que parece indicar que o processo magmático se fez através de pulsos distintos na região estudada.

As regiões de afloramento dos derrames distri- buem-se em duas porções distintas. A primeira ao norte da área investigada compreendendo as cidades de Ribeirão Preto, Franca e Jaboticabal e a segunda, mais ao sul, compreendendo as cidades de Botucatu, Jaú e Brotas. Esses basaltos estão assentados diretamente, de modo concordante horizontal ou subhorizontal, sobre os arenitos eólicos da Formação Botucatu, como mostra a figura 6.

Com o intuito de facilitar a abordagem petrográfica e geoquímica, as rochas de natureza intrusiva que ocorrem na região estudada foram divididas em cinco grupos distintos, considerando-se apenas as suas áreas de ocorrência, assim denominados: denominados por Cajuru, Leme, Iracemápolis, Campinas e São Sebastião do Paraíso, conforme mostra o mapa da figura 3.

ASPECTOS PETROGRÁFICOS De maneira geral, a mineralogia modal destas rochas é composta essencialmente por $25 \%$ a $50 \%$ de plagioclásio, normalmente labradorita, $20 \%$ a $40 \%$ de piroxênios, representados pela augita e pigeonita, até $4 \%$ de olivina

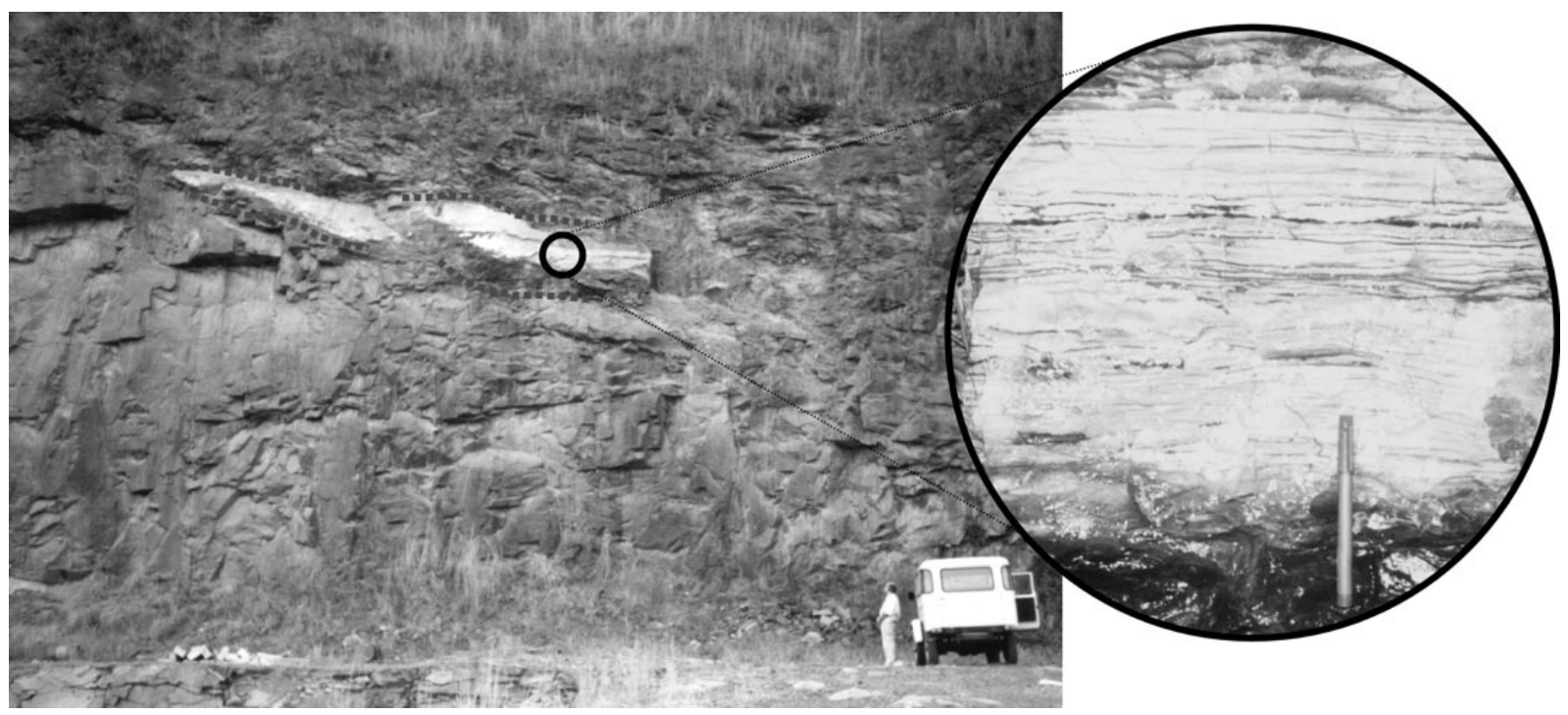

Figura 4 - Grande bloco de calcário (em destaque), pertencente à porção inferior da Formação Corumbataí, na forma de xenólito, engolfado pelo sill de diabásio. No detalhe, a feição da rocha, próximo à cidade de Rio Claro (SP). 


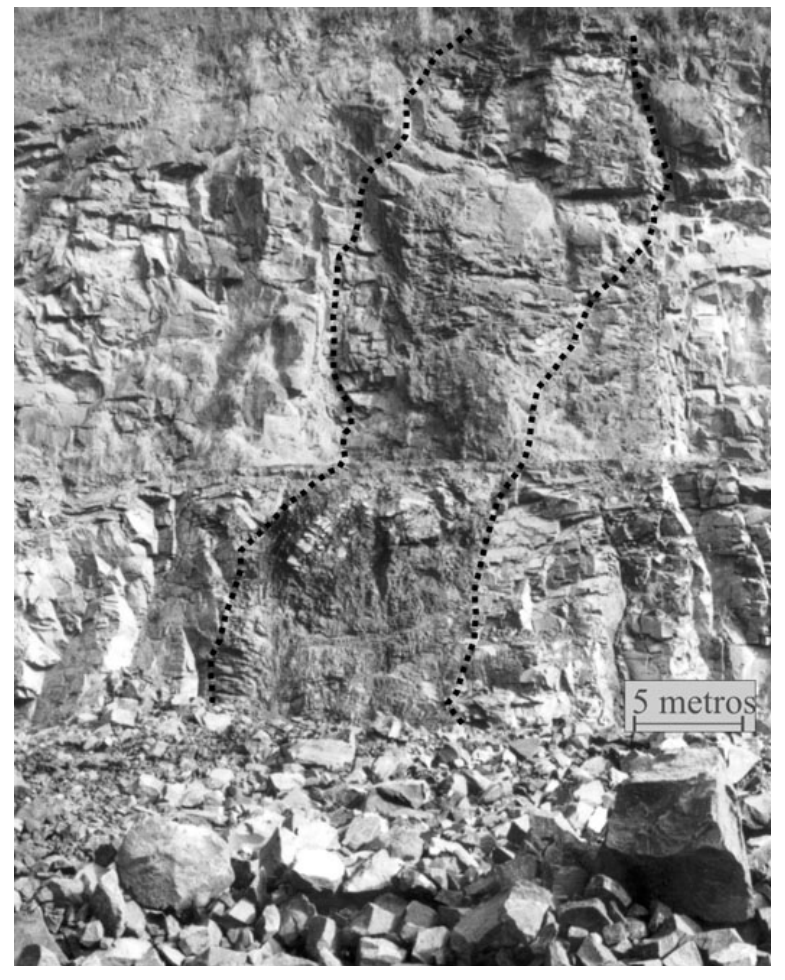

Figura 5 - Dique de diabásio (rocha mais escura em destaque), cortando sill (rocha mais clara) localizado próximo à cidade de Rio Claro.

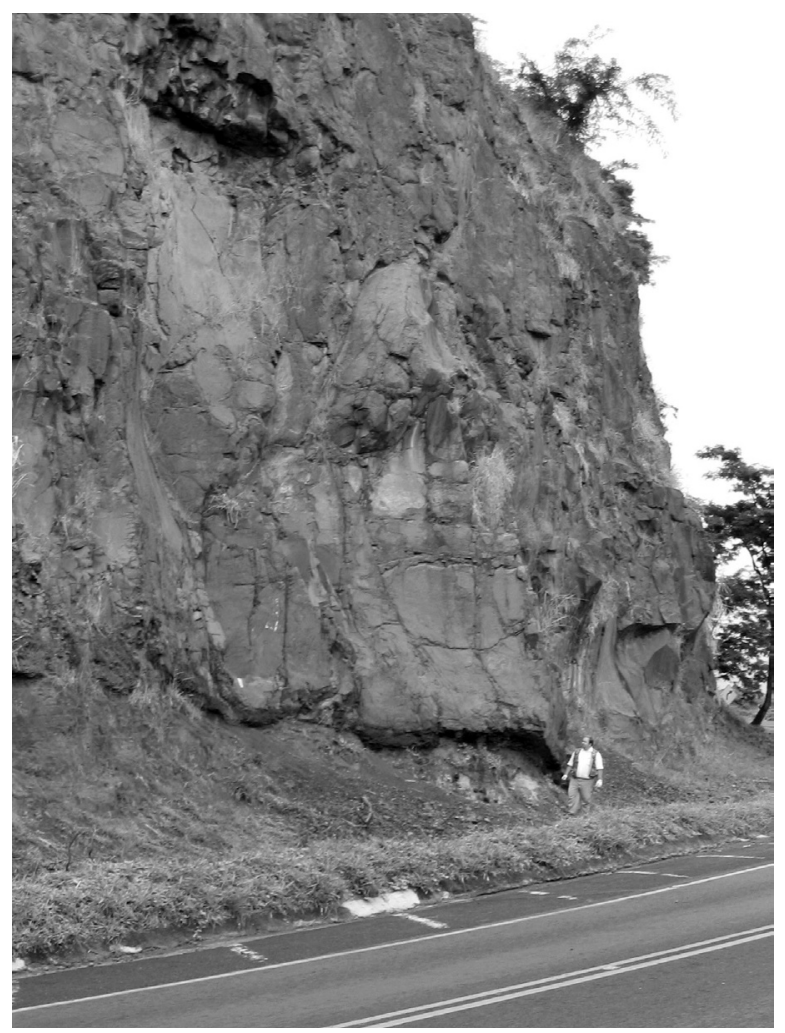

Figura 6-Contato, concordante e subhorizontal, dos derrames da Formação Serra Geral com os arenitos da Formação Botucatu. Afloramento localizado próximo à cidade de Brotas. comumente na forma de pseudomorfos, de $4 \%$ a $10 \%$ de minerais opacos (magnetita e ilmenita) e mesóstase (vítrea ou microgranular) que chega a representar nas rochas com textura intergranular, até $40 \%$ do volume total da rocha.

As rochas estudadas, tanto as provenientes de derrames como as intrusivas, possuem coloração variando de cinza até negra (Fig. 7), com tons mais ou menos esverdeados, predominantemente mesocráticas, embora também ocorram termos mais leucocráticos, como é o caso do diabásio encontrado em pedreiras próximo a cidade de Limeira.

São em sua maioria holocristalinas, contudo deve-se ressaltar que o grau de visibilidade dos minerais constituintes e a presença de vidro, estão diretamente relacionadas com as condições de cristalização da rocha, ou seja aquelas com resfriamento rápido observadas em topo de derrame e as provenientes de diques e sills poucos espessos, tendem a desenvolver características afaníticas em função do volume de material vítreo presente na mesóstase. Com isso, as rochas estudas são em sua grande maioria, inequigranulares e, por vezes, porfiríticas.

Registra-se que foram também observadas rochas com granulação grossa (Fig. 8), com índice de coloração mesocrático a leucocrático, com menos de $35 \%$ de minerais máficosprincipalmente nos corpos intrusivos próximos a Campinas, cuja origem pode estar relacionada a um processo de cristalização fracionada

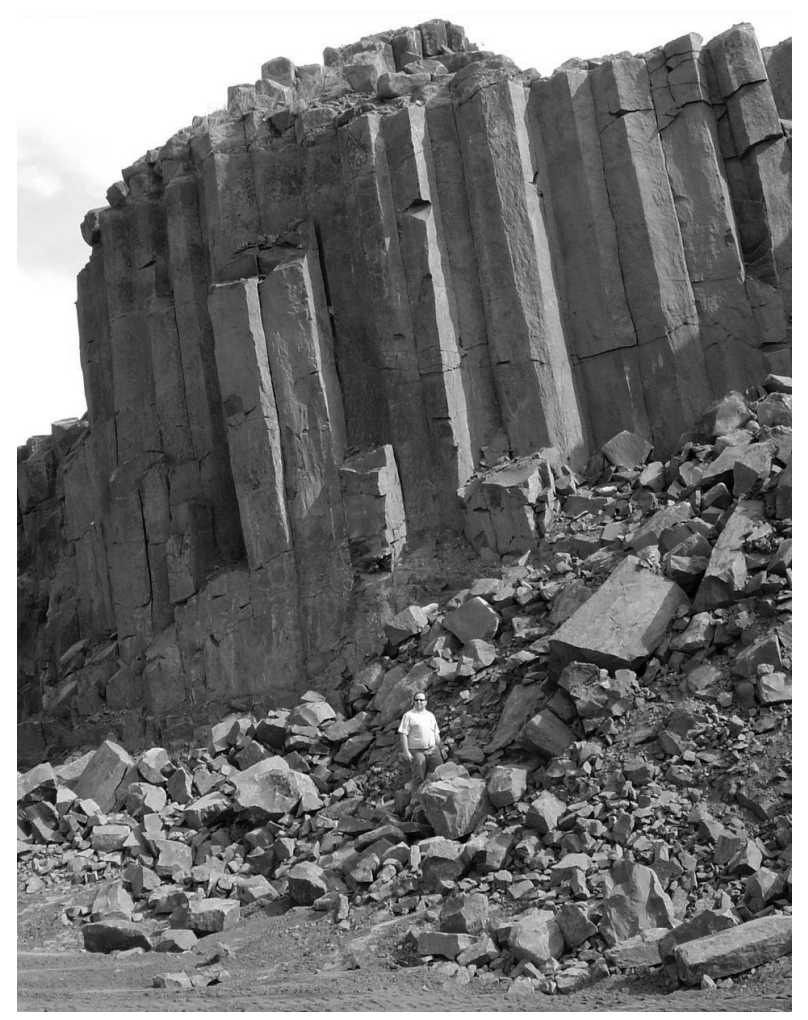

Figura 7 - Pedreira de diabásio, com coloração acinzentada, mesocrática com disjunções colunares proeminentes, em sill próximo a cidade de Campinas. 
em equilíbrio em um meio enriquecido em voláteis, o que propiciou o desenvolvimento de uma granulação pegmatítica.

De maneira geral a grande maioria das rochas intrusivas e extrusivas apresentam textura intergranular, onde cristais euhédricos e subhédricos ripiformes de plagioclásio apresentam grãos intersticiais de piroxênio, figura 9. Entretanto considerando-se os diferentes fatores envolvidos no processo de cristalização magmática (eg. taxa de resfriamento, viscosidade, teor de

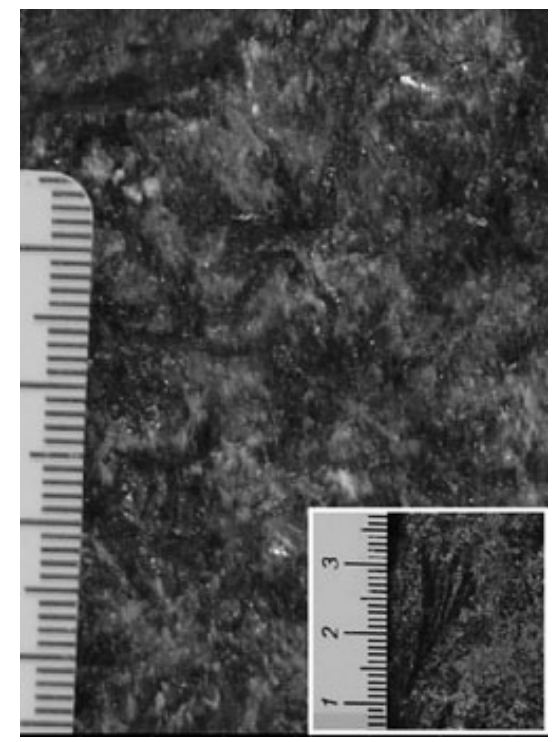

Figura 8 - Diabásio com granulação grossa (pegmatítica), com grandes cristais de piroxênio (augita) aciculares (no detalhe). Amostra coletada em sill localizado próximo à cidade de Campinas.

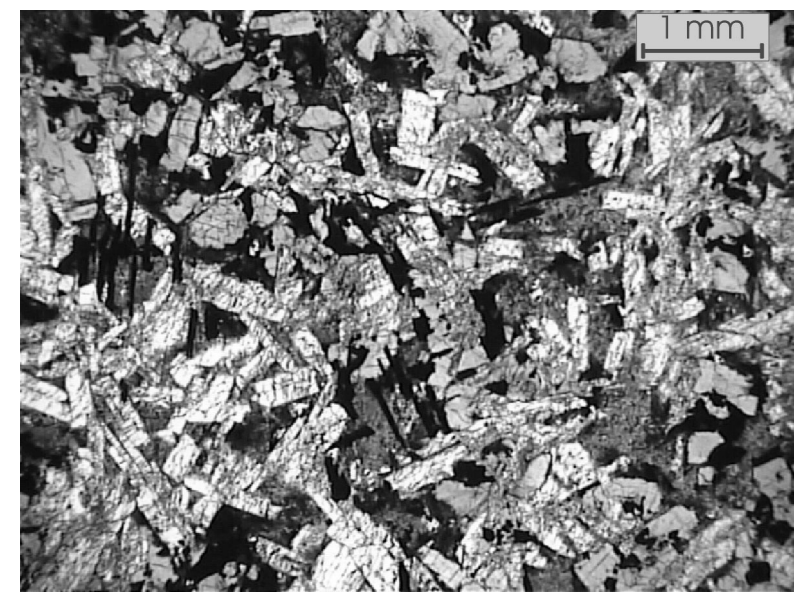

Figura 9 - Diabásio com textura intergranular, onde cristais ripiformes de plagioclásio apresentam grãos intersticiais de clinopiroxênio, além de minerais opacos subhedrais. Amostra coletada em sill no distrito de Assistência, próximo à cidade de Rio Claro. Nicóis paralelos. voláteis, etc) há o desenvolvimento de uma variedade de texturas intergranulares como a subofítica, figura 10 e ofítica, figura 11 (comuns em rochas com resfriamento mais lento, como porções interiores dos derrames e sills espessos), além de granofírica (Fig. 12), intersertal (Fig. 13), pilotaxítica (Fig. 14) e hialofítica (Fig. 15), todas elas indicativas de resfriamento rápido, correspondendo a topo de derrames, borda de sills e diques poucos espessos.

Além da mineralogia já citada, destaca-se em quantidades subordinadas a presença de apatita, além de minerais secundários, principalmente a celadonita, além de quartzo (preenchendo veios e cavidades), car-

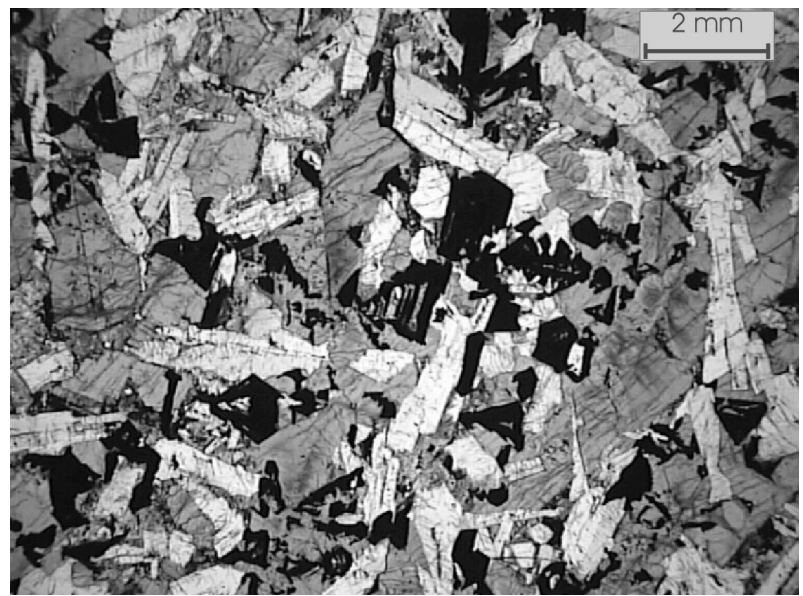

Figura 10 - Amostra de diabásio, coletada em sill próximo a cidade Campinas, exibindo textura subofitica, onde cristais ripiformes de plagioclásio encontram-se parcialmente engolfados por cristais de piroxênio (cor acastanhada), também ocorrem minerais opacos. Nicóis paralelos.

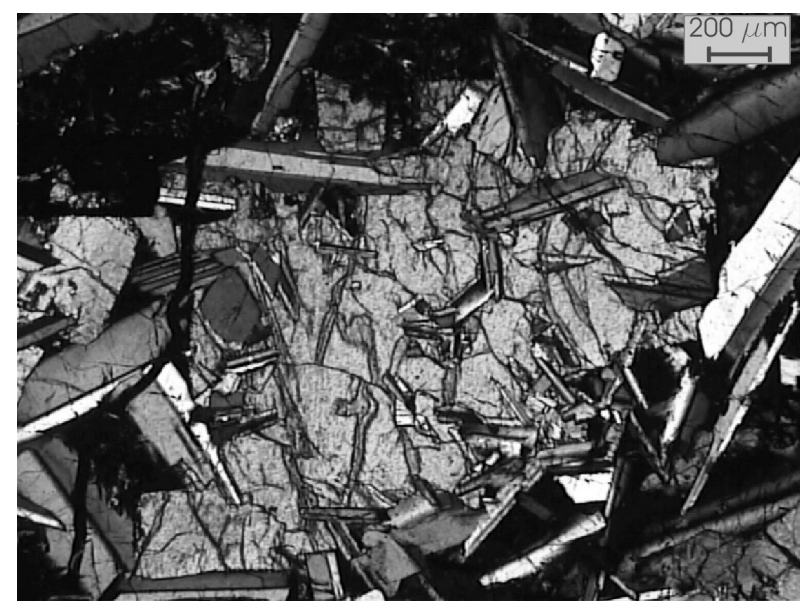

Figura 11 - Basalto coletado em derrame próximo a cidade de São Carlos, exibindo localmente textura ofitica, onde cristais ripiformes de plagioclásio são envolvidos totalmente por cristal de piroxênio prismático. Observam-se também minerais opacos e mesóstase microgranular. Nicóis cuzados. 


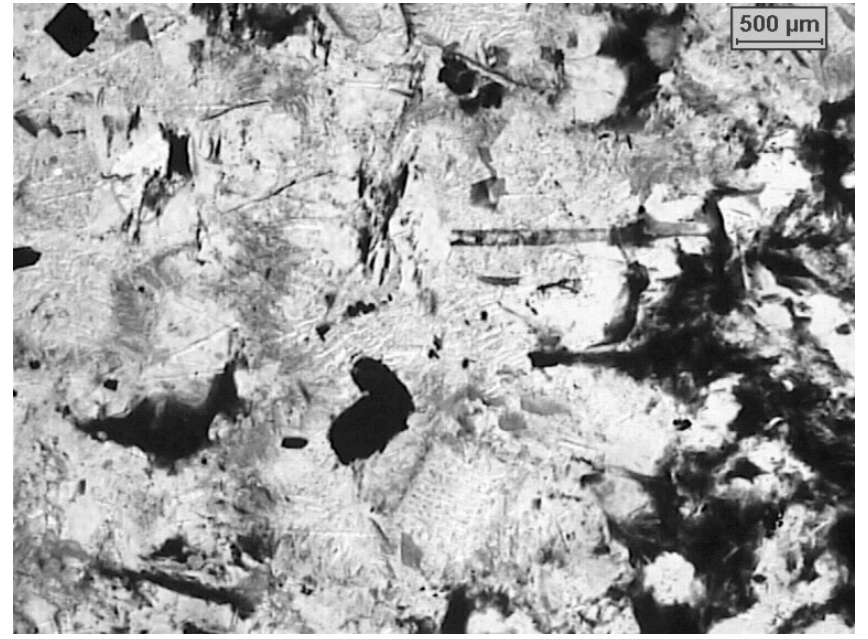

Figura 12 - Diabásio coletado em dique próximo a cidade de Rio Claro, exibindo textura granofirica, com material de composição félsica microgranular, com forma vermicular, conferindo aspecto gráfico. Ocorrem também minerais opacos, mesóstase microgranular e cristais prismáticos de plagioclásio. Nicóis cruzados.

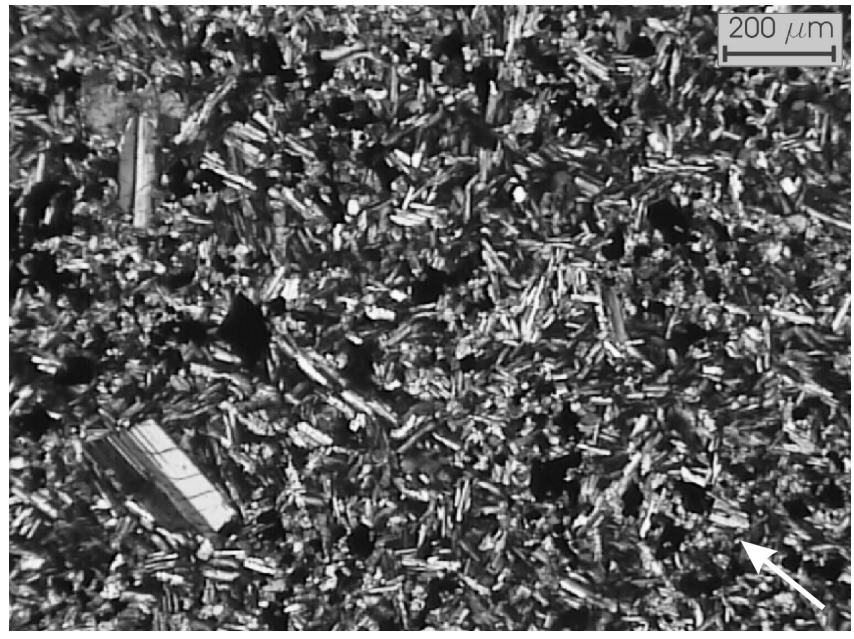

Figura 14 - Amostra coletada em derrame, próximo à cidade de Ribeirão Preto, com ocorrência de textura pilotaxitica, onde cristais ripiformes de plagioclásio estão orientados segundo direção de fluxo da lava (seta). Nicóis cruzados.

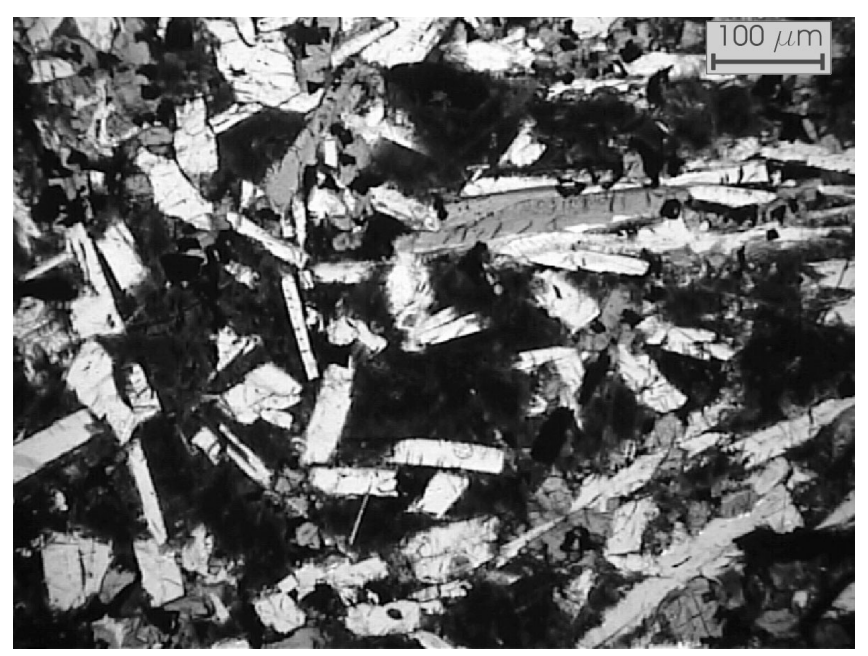

Figura 13 - Textura intersertal em amostra coletada próximo a cidade de Iracemápolis. O material vitreo, rico em cristalitos, ocupa os interstícios dos cristais ripiformes de plagioclásio. Nicóis paralelos.

bonato e clorita, raros cristais de zircão, epidoto, titanita, anfibólio e biotita.

ASPECTOS LITOGEOQUÍMICOS As 105 amostras coletadas durante as várias etapas de campo realizadas na região foram analisadas sob microscopia de luz polarizada, de forma a selecionar apenas as que apresentassem o mínimo possível de minerais secundários e amígdalas. Desta forma, obteve-se um conjunto de 76 amostras, com valores de P.F. menores do que $1 \%$, sendo que 20 delas são de derrames (basaltos) e as outras 56 de corpos intrusivos (diabásios), principalmente sills.

As amostras foram analisadas para elementos

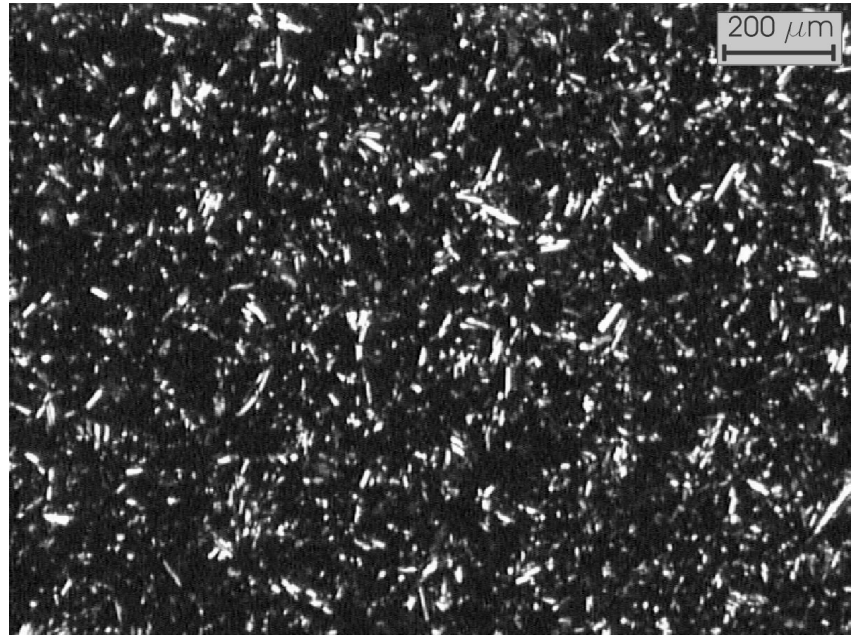

Figura 15 - Textura hialofitica em amostra coletada em derrame, na Serra do Canta Galo, próximo à cidade de Rio Claro, onde cristais ripiformes de plagioclásio encontram-se dispersos em mesóstase vítrea. Nicóis cruzados.

maiores, menores e traços por fluorescência de raios-X, no Laboratório de Geoquímica do Departamento de Petrologia e Metalogenia - IGCE/UNESP (Campus Rio Claro), empregando-se para os primeiros analitos fundidos em meio borato promovendo resultados com erros analíticos inferiores a 3\%. Os elementos traços por sua vez foram analisados em pastilhas de pó prensado $\left(30 \mathrm{t} / \mathrm{cm}^{2}\right)$ com erros relativos inferiores a $5 \%$.

Detalhes acerca da preparação das amostras e dos procedimentos envolvidos podem ser verificados em Nardy et al. (1997).

A tabela 2 lista parte dos resultados obtidos, representativos das áreas de ocorrência, conforme o crité- 
Geologia e aspectos petrológicos das rochas intrusivas e efusivas mesozóicas de parte da borda leste da bacia do Paraná em São Paulo

Tabela 2 - Resultados geoquímicos e norma CIPW, de amostras representativas da área de estudo com LOI $<1 \%$ e $\mathrm{SiO}_{2}<51 \%$. Para o calculo da norma $\mathrm{CIPW}$ foi empregado $\mathrm{Fe}_{2} \mathrm{O}_{3} / \mathrm{FeO}=0,15$.

\begin{tabular}{|c|c|c|c|c|c|c|c|c|}
\hline Amostras & KS 540 & KS 542 & KS 601 & KS 602 & KS 563 & KS 569 & KS 614 & KS 621 \\
\hline \multirow{2}{*}{$\begin{array}{l}\text { Região } \\
\text { (Fig.3) }\end{array}$} & Iracemápolis & Iracemápolis & Campinas & Campinas & Cajuru & Franca & Franca & Franca \\
\hline & Sill & Sill & Sill & Sill & Sill & Derrame & Derrame & Derrame \\
\hline Subgrupo & Pitanga & Pitanga & Paranapanema & Paranapanema & Paranapanema & Urubici & Urubici & Urubici \\
\hline $\mathrm{SiO}_{2}$ & 48,97 & 50,32 & 49,05 & 50,29 & 50,18 & 50,75 & 50,81 & 49,36 \\
\hline $\mathrm{TiO}_{2}$ & 3,66 & 3,75 & 2,64 & 3,95 & 3,73 & 3,37 & 3,86 & 4,03 \\
\hline $\mathrm{Al}_{2} \mathrm{O}_{3}$ & 13,09 & 13,17 & 13,39 & 12,88 & 12,92 & 13,35 & 13,25 & 13,88 \\
\hline $\mathrm{Fe}_{2} \mathrm{O}_{3}$ & 15,20 & 15,02 & 15,40 & 15,82 & 16,04 & 14,44 & 14,11 & 14,21 \\
\hline $\mathrm{MnO}$ & 0,15 & 0,14 & 0,15 & 0,13 & 0,12 & 0,17 & 0,23 & 0,11 \\
\hline $\mathrm{MgO}$ & 5,40 & 4,08 & 5,64 & 4,19 & 4,77 & 4,95 & 4,10 & 4,54 \\
\hline $\mathrm{CaO}$ & 8,44 & 8,14 & 9,70 & 7,97 & 8,06 & 9,15 & 7,78 & 8,27 \\
\hline $\mathrm{Na}_{2} \mathrm{O}$ & 2,67 & 2,79 & 2,44 & 2,89 & 2,74 & 2,43 & 3,01 & 3,04 \\
\hline $\mathrm{K}_{2} \mathrm{O}$ & 1,43 & 1,57 & 1,11 & 1,71 & 1,51 & 1,39 & 1,54 & 1,39 \\
\hline $\mathrm{P}_{2} \mathrm{O}_{5}$ & 0,56 & 0,54 & 0,35 & 0,68 & 0,54 & 0,43 & 0,64 & 0,67 \\
\hline P.F. & 0,43 & 0,48 & 0,36 & 0,13 & 0,09 & 0,19 & 0,74 & 0,87 \\
\hline Soma & 100,01 & 100,00 & 100,24 & 100,65 & 100,69 & 100,63 & 100,08 & 100,35 \\
\hline
\end{tabular}

Norma CIPW

\begin{tabular}{c|c|c|c|c|c|c|c|c}
\hline $\mathrm{Q}$ & 0.00 & 2.50 & 0.00 & 1.54 & 1.31 & 10.02 & 3.09 & 0.63 \\
\hline $\mathrm{Or}$ & 8.45 & 9.28 & 6.56 & 10.11 & 8.92 & 6.61 & 9.10 & 8.22 \\
\hline $\mathrm{Ab}$ & 22.59 & 23.61 & 20.64 & 24.45 & 23.18 & 17.55 & 25.47 & 25.72 \\
\hline $\mathrm{An}$ & 19.51 & 18.78 & 22.31 & 17.13 & 18.50 & 17.23 & 18.10 & 20.13 \\
\hline $\mathrm{Di}$ & 15.59 & 15.20 & 19.66 & 15.13 & 15.07 & 17.03 & 13.68 & 13.80 \\
\hline $\mathrm{Hy}$ & 21.63 & 18.94 & 18.79 & 20.09 & 22.26 & 19.02 & 18.41 & 19.12 \\
\hline $\mathrm{Ol}$ & 0.67 & 0.00 & 3.16 & 0.00 & 0.00 & 0.00 & 0.00 & 0.00 \\
\hline $\mathrm{Mt}$ & 2.88 & 2.84 & 2.91 & 2.99 & 3.03 & 2.64 & 2.67 & 2.69 \\
\hline $\mathrm{Il}$ & 6.95 & 7.12 & 5.01 & 7.50 & 7.08 & 9.44 & 7.33 & 7.65 \\
\hline $\mathrm{Ap}$ & 1.33 & 1.28 & 0.83 & 1.61 & 1.28 & 0.45 & 1.52 & 1.59 \\
\hline
\end{tabular}

Elementos Traços (ppm)

\begin{tabular}{c|c|c|c|c|c|c|c|c}
\hline $\mathrm{Cr}$ & 115 & 92 & 153 & 134 & 82 & 163 & 138 & 98 \\
\hline $\mathrm{Ni}$ & 40 & 16 & 57 & 57 & 25 & 58 & 45 & 49 \\
\hline $\mathrm{Cu}$ & 68 & 219 & 203 & 200 & 97 & 156 & 87 & 88 \\
\hline $\mathrm{Ba}$ & 501 & 514 & 378 & 358 & 482 & 420 & 539 & 560 \\
\hline $\mathrm{Rb}$ & 30 & 32 & 26 & 26 & 35 & 30 & 50 & 40 \\
\hline $\mathrm{Sr}$ & 448 & 436 & 361 & 347 & 463 & 619 & 672 & 652 \\
\hline $\mathrm{Y}$ & 25 & 29 & 20 & 21 & 18 & 21 & 27 & 21 \\
\hline $\mathrm{Zr}$ & 226 & 248 & 164 & 166 & 248 & 263 & 285 & 285 \\
\hline $\mathrm{Nb}$ & 21 & 23 & 15 & 15 & 20 & 20 & 26 & 27 \\
\hline
\end{tabular}


rio adotado no mapa geológico da figura 3.

Classificação e nomenclatura Os dados geoquímicos obtidos foram então projetados em diversos diagramas com o intuito de caracterizar as rochas intrusivas e os derrames que ocorrem na região estudada. As amostras foram classificadas como sendo subalcalinas, segundo o diagrama sílica x álcalis (TAS) de Zanettin (1984) e Le Bas et al. (1986), e toleíticas (Irvine \& Baragar, 1971) no diagrama AFM, figuras 16 e 17, fato este confirmado pela mineralogia modal observada, com a presença de dois piroxênios (augita e pigeonita) e pela presença de quartzo e hiperstênio normativos (Tab. 2).

Deve-se ressaltar que nos diagramas do tipo TAS, figura 16, os basaltos apresentam concentrações de sílica variando de $48,91 \%$ até $51,92 \%$ e álcalis de $3,65 \%$ a $4,99 \%$, estando dispostos no campo do basalto toleítico. Por sua vez, os diabásios apresentam uma maior variação de sílica (de $47,77 \%$ a $55,31 \%$ e álcalis entre $3,59 \%$ e $6,44 \%$ ) em relação aos basaltos e distribuem-se pelo campo do basalto toleítico, do traquibasalto e do traqui andesito, este último representado por 4 amostras de natureza leucocrática, de acidez intermediária, com tendência mais sódico-potássica, provenientes da região de Iracemápolis, próximos à cidade de Limeira (Pedreira Cavinato).

Elementos maiores e menores Para uma melhor caracterização e comparação entre as rochas intrusivas e as extrusivas, foram construídos diversos diagramas de variação empregando-se as concentrações de elementos maiores, menores e traços em função do $\mathrm{MgO}$, como mostra os diagramas da figuras 18 e 19. A avaliação preliminar destes diagramas mostra que as rochas intrusivas possuem características geoquímicas semelhantes daquelas extrusivas, formando em vários
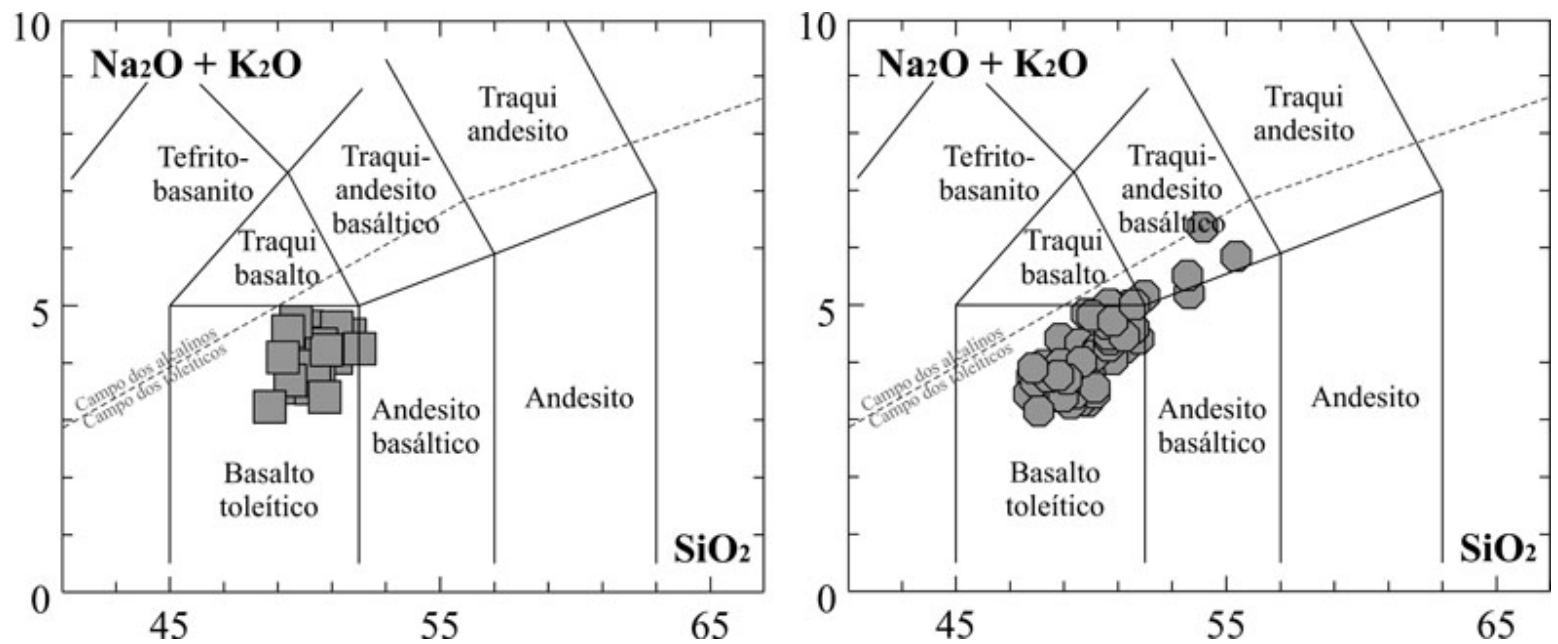

Figura 16 - Diagrama de nomenclatura dos corpos básicos estudados segundo o esquema TAS de Zanettin (1984), com campos modificados por Le Bas et al.(1986). A linha tracejada separa os campos dos alcalinos e toleíticos (Irvine \& Baragar, 1971). Legenda: quadrados-derrames; círculos - rochas intrusivas.
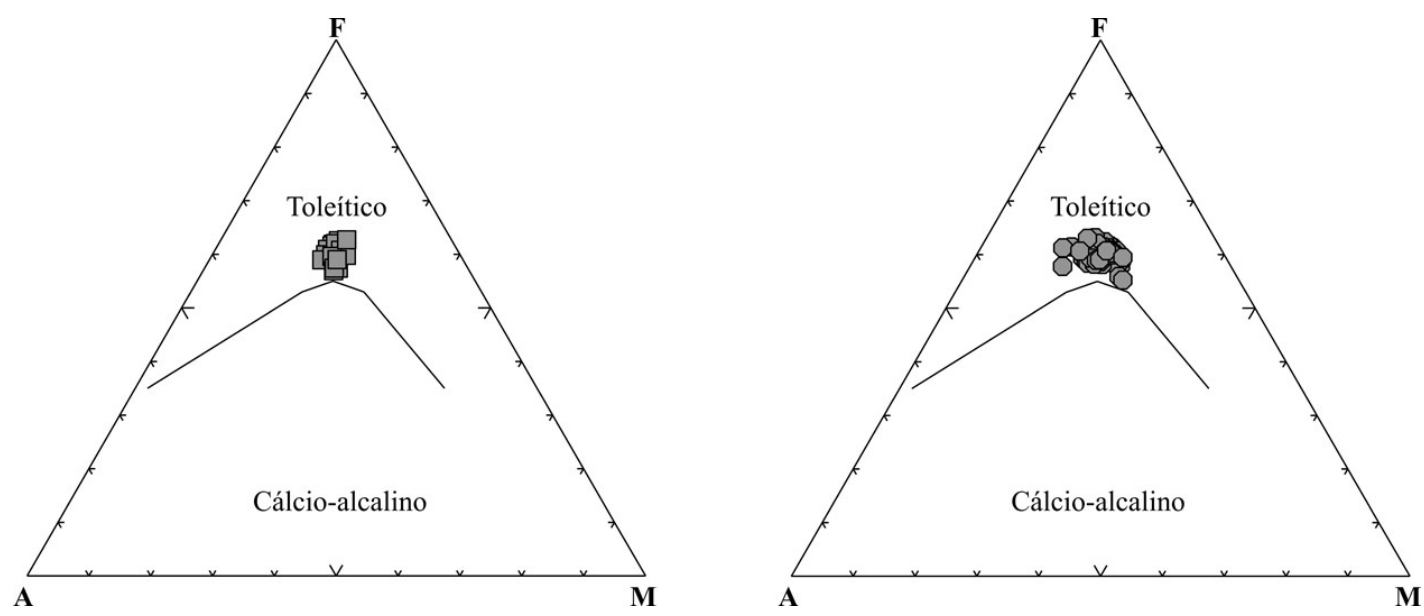

Figura 17 - Diagrama do tipo $\boldsymbol{A}\left(\mathrm{Na}_{2} \mathrm{O}+\mathrm{K}_{2} \mathrm{O}\right)$ - $\boldsymbol{F}\left(\mathrm{Fe}_{2} \mathrm{O}_{3}\right)-\boldsymbol{M}(\mathrm{MgO})$ dos corpos básicos estudados, com linha divisória entre os campos segundo Irvine \& Baragar (1971). Legenda: quadrados - derrames; círculos - rochas intrusivas. 

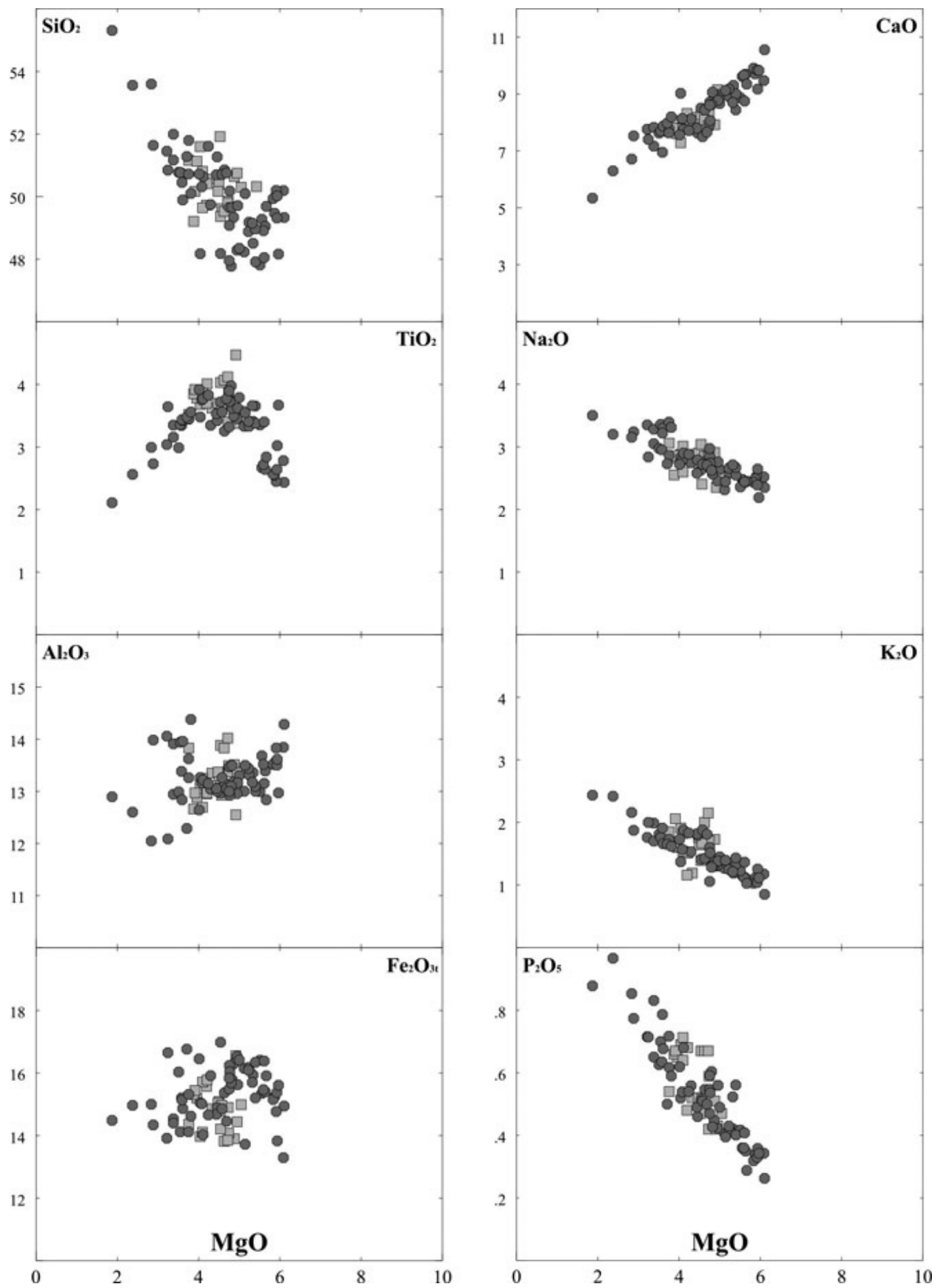

Figura 18 - Diagrama de variação de elementos maiores e menores (\%) em função do $\mathrm{MgO}(\%)$ dos corpos investigados. Legenda: quadrados - derrames; círculos - rochas intrusivas.

diagramas trends bem definidos com o aumento das concentrações de $\mathrm{SiO}_{2}, \mathrm{Na}_{2} \mathrm{O}, \mathrm{K}_{2} \mathrm{O}$ e $\mathrm{P}_{2} \mathrm{O}_{5}$, e diminuição de $\mathrm{CaO}$, com o incremento do grau de evolução da rocha. Nesses diagramas, as amostras mais evoluídas (ou diferenciadas), com concentrações de $\mathrm{MgO}$ variando entre $1,87 \%$ e $3,38 \%$, são aquelas provenientes do sill de Iracemápolis, em especial aquelas da Pedreira Cavinato, enquanto que as mais"primitivas" (ou menos diferenciadas), valores de $\mathrm{MgO}$ situados entre 4,04\% e
6,11\%, são os diabásios coletados no sill de Campinas. $\mathrm{O}$ diagrama $\mathrm{MgO}$ x $\mathrm{TiO}_{2}$ da figura 18, mostra que todas as amostras coletadas, de basaltos e diabásios, possuem concentrações em $\mathrm{TiO}_{2}$ superior a $2 \%$. Além disso, destaca-se neste mesmo diagrama, um conjunto de basaltos com concentrações de $\mathrm{TiO}_{2}$ acima de $4 \%$, que ocorrem ao norte da região de Franca, próximo ao Rio Grande. Estes basaltos também se destacam nos diagramas de $\mathrm{K}_{2} \mathrm{O}$ e $\mathrm{P}_{2} \mathrm{O}_{5}$. Também nesta mesma figura, 

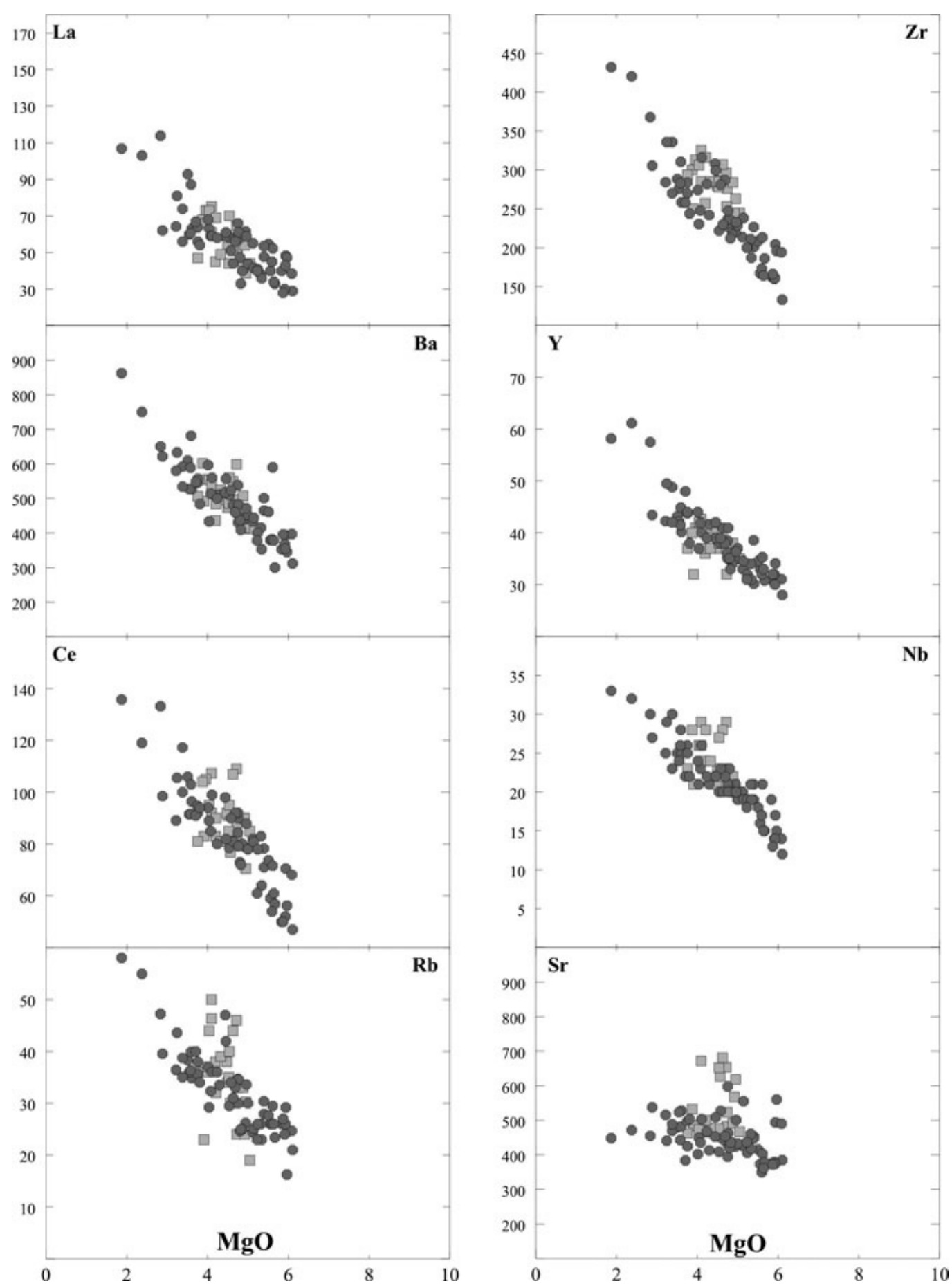

Figura 19 - Diagrama de variação de elementos traços (ppm) em função do $\mathrm{MgO}(\%)$ dos corpos investigados. Legenda: quadrados-derrames; círculos-rochas intrusivas.

as rochas leucocráticas do sill de Iracemápolis e os diabásios da região de Campinas apresentam as menores concentrações em $\mathrm{TiO}_{2}$.

Elementos traços As análises espectrométricas por fluorescência de raios-x mediram as concentrações de $\mathrm{Cr}, \mathrm{Ni}$. Ba, Rb, Sr, La, Ce Zr, Y e Nb dos basaltos e diabásios que ocorrem na região estudada. Empregando estes resultados, foram construídos diversos diagramas de variação utilizando-se do $\mathrm{MgO}$ como índice de evolução magmática. A exemplo do observado para os elementos maiores e menores, há formação de trends relativamente bem definidos envolvendo basaltos e diabásios, com aumento nas concentrações de $\mathrm{La}, \mathrm{Ce}, \mathrm{Ba}$, $\mathrm{Zr} \mathrm{Y}, \mathrm{Nb}, \mathrm{Rb}$ e $\mathrm{Sr}$ com o grau de evolução das rochas. Entretanto os basaltos da região de Franca com maiores concentrações em $\mathrm{TiO}_{2}$ observados nos diagramas da figura 19, também apresentam maiores concentrações de Ce (>100ppm ), Nb (>25 ppm) Rb (>40 ppm) e Sr $(>600 \mathrm{ppm})$ e assim destacando-se em relação às de- 
mais amostras da região.

A partir destas observações e, para uma comparação mais efetiva entre as rochas observadas, foi construído um diagrama multielementar (spidergrams), com o mostra a figura 20, normalizados em relação ao manto primordial, segundo McDonough \& Sun (1995), com algumas das amostras representativas da área estudada, e que se encontram listadas na tabela 2. Neles observa-se que a amostra da região de Franca (KS-617) é mais enriquecida em elementos incompatíveis do que aquelas das demais regiões, enquanto que aquela da região de Campinas (KS-556) a mais empobrecida nos mesmos elementos.

Os dados geoquímicos até agora analisados revelam a existência de pelo menos três grandes grupos

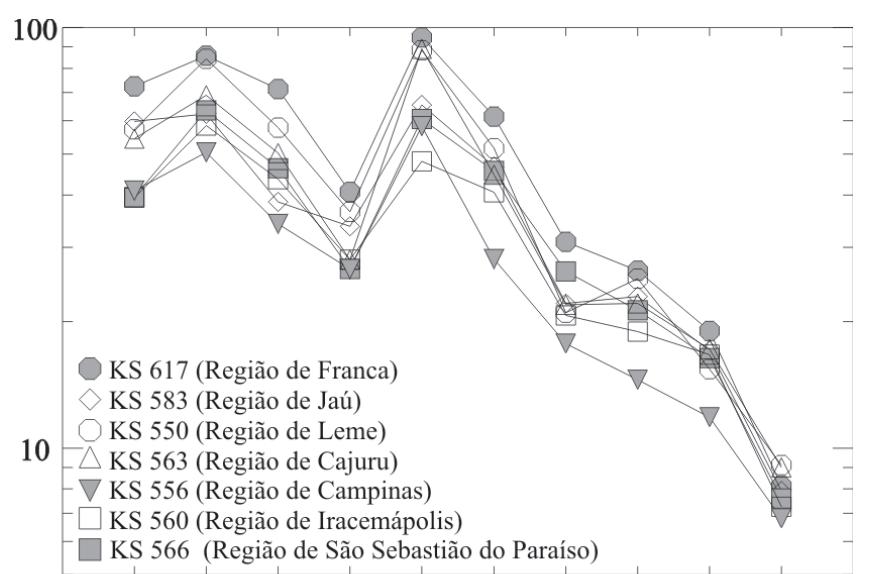

$\begin{array}{llllllllll}\mathrm{Rb} & \mathrm{Ba} & \mathrm{K} & \mathrm{Nb} & \mathrm{La} & \mathrm{Ce} & \mathrm{Sr} & \mathrm{Zr} & \mathrm{Ti} & \mathrm{Y}\end{array}$

Figura 20 - Diagrama multielementar (spidergrams) normalizado em relação ao manto primordial (McDonough \& Sun, 1995), de algumas amostras representativas relacionadas na tabela 2 .

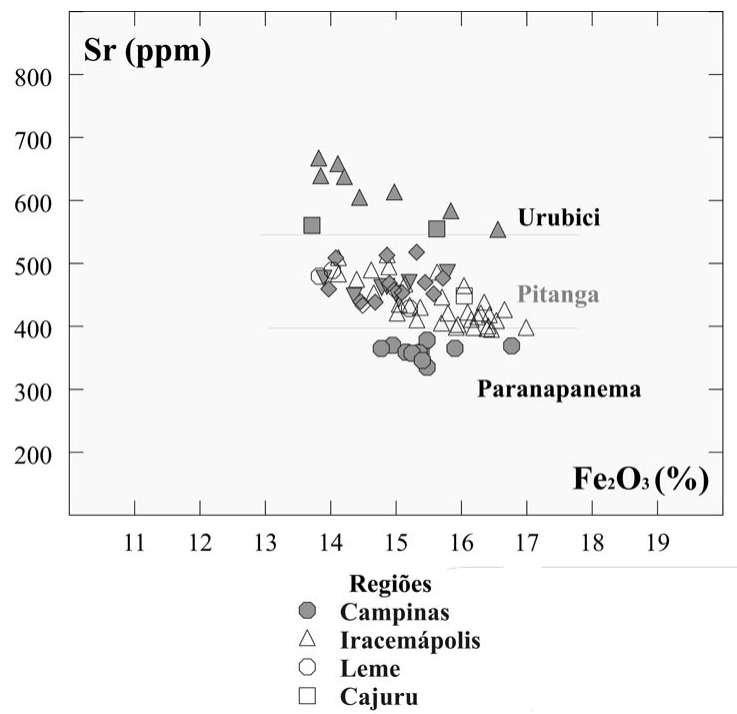

de rochas assim discriminados: o diabásio da região de Campinas; os diabásios das regiões de Iracemápolis (KS-560), Leme (KS-550) e Cajuru (KS-563) além dos basaltos da região de Franca (KS-617) e Jaú (KS-563); e o terceiro correspondendo aos basaltos que ocorrem ao norte da região de Franca, próxima ao Rio Grande (KS-614) e os diabásios de São Sebastião do Paraíso (KS-566), figura 3. Além disso, considerando-se a classificação dos basaltos ATi sugerida por Peate et al. (1992) e apresentada nos diagramas da figura 21, verifica-se que os grupos discriminados acima dispõe-se em campos distintos. $\mathrm{O}$ do primeiro grupo, no campo do magma-tipo Paranapanema, o segundo, no campo Pitanga e o terceiro no campo dos basaltos do tipo Urubici. As rochas deste último grupo (Urubici) apresentam as mais elevadas concentrações de $\mathrm{Sr}$ (entre $555 \mathrm{pm}$ e $681 \mathrm{ppm}$ ) e relações Ti/Y variando entre 567 e 766 em relação aos demais. Além disso, essas rochas apresentam os mais altos valores em $\mathrm{TiO}_{2}$ do que dos demais grupos, variando de $3,47 \%$ a $4,47 \%$ (Fig. 18).

Os diabásios do tipo Pitanga, são caracterizados por concentrações de Sr entre 395 ppm a 532 ppm e razões Ti/Y variando entre 415 e 734, além de possuírem concentrações em $\mathrm{TiO}_{2}$ entre de 2,99\% a 4,01\%.

Por fim, as amostras do tipo Paranapanema, coletadas nos corpos intrusivos das regiões de Campinas, apresentam baixas concentrações em $\mathrm{Sr}$, entre $350 \mathrm{ppm}$ e 385 ppm, e Ti/Y de 435 a 553, com concentrações em $\mathrm{TiO}_{2}$ variando no intervalo de $2,44 \%$ a $2,84 \%$, ou seja o mais baixo em relação aos dois outros grupos.

Cabe ressaltar que as amostras provenientes dos sills com alto teor de $\mathrm{SiO}_{2}$, sendo classificados como traqui-andesito-basalto, de acordo com o diagrama TAS da figura 17 , não foram consideradas nesta classificação por não se tratarem de rochas tipicamente básicas e sim de caráter intermediário.

Figura 21 - Comportamento das amostras coletadas na área investigada nos diagramas discriminatórios $\mathrm{Fe}_{2} \mathrm{O}_{3}$ x $\mathrm{Sr}$ e $\mathrm{Sr} \times \mathrm{Ti} / \mathrm{Y}$, para os magmas basálticos da PMP, com campos definido por Peate et al. (1992). 
Elementos terras raras (ETR) Com o intuito de melhor caracterizar os subgrupos de rochas observados foram escolhidas 8 amostras representativas para a determinação das concentrações de ETR. Para tanto as amostras foram dissolvidas em meio ácido e levadas à separação cromatográfica em resinas de troca iônica. A determinação de suas concentrações foi feita através de espectrometria de emissão em plasma indutivamente acoplado (ICP-OES), nas dependências do Laboratório de Geoquímica do Departamento de Petrologia e Metalogenia - IGCE/UNESP (Campus Rio Claro), utilizando um sistema de nebulização ultrassônica, conforme o método publicado em Malagutti et al. (1998). Os resultados obtidos, que estão listados na tabela 2, foram lançados em diagramas multi elementar (Fig. 22), normalizados em relação ao manto primordial, segundo McDonough \& Sun (1995), representando-se separadamente os três grupos de rochas vulcânicas discriminadas anteriormente, figura 21. De maneira geral, observou que todas elas apresentam praticamente um mesmo padrão de distribuição, com pequenas anomalias de Eu, e enriquecimento em ETR leves em relação às pesadas.

As amostras de diabásio do tipo Pitanga (Fig. 22A) coletadas na região de Iracemápolis (KS 540 e KS 542) e de Cajuru (KS 563) apresentam valores de $(\mathrm{La} / \mathrm{Lu})_{\mathrm{n}}$ variando de 6,93 até 9,05 e leves anomalias negativas de $\mathrm{Eu}\left(\mathrm{Eu} / \mathrm{Eu}^{*}\right.$, de 0,94 a 0,97). As amostras de diabásio do tipo Paranapanema (Fig. 22B) mostram um menor enriquecimento em ETR leves, com $(\mathrm{La} / \mathrm{Lu})$ $\mathrm{n}$ variando de 6,73 ate 8,04 e anomalias levemente positivas $\left(\mathrm{Eu} / \mathrm{Eu}^{*}=1,03\right)$ e negativas $\left.<\mathrm{Eu} / \mathrm{Eu}^{*}=0,9\right)$. Já os padrões de distribuição das amostras do tipo Urubici (Fig. 22C), mostram um enriquecimento um pouco maior de ETR leves em relação aos grupos anteriores, com . (La/Lu)n variando de 8,93 até 11,58 para as três amostras selecionadas, ocorrendo também leves anomalias negativas de $\mathrm{Eu}\left(0,95<\mathrm{Eu} / \mathrm{Eu}^{*}<0,98\right)$.

DISCUSSÕES E CONCLUSÕES Os dados geoquímicos mostram que na área investigada ocorrem rochas vulcânicas pertencentes exclusivamente ao grupo alto em $\mathrm{TiO}_{2}$, que podem ser divididos em três magmas distintos denominados Pitanga, Paranapanema e Urubici, cuja distribuição pela área estudada se faz de forma relativamente bem definida, conforme mostra o mapa da figura 23. De maneira geral os derrames observados na região de Jaú e naquela da região de Franca abaixo do Rio Sapucaí Mirim, são do tipo Pitanga. Já acima do referido rio os derrames apresentam afinidades geoquímicas do subgrupo Urubici.

Os diagramas das Figs. 18 e 19 mostraram que as rochas intrusivas se diferenciam dos derrames por uma maior variação nas concentrações dos elementos maiores, menores e traços. De fato, esta diferença deve estar relacionada com processos diferenciação magmática, mais efetivo em rochas intrusivas, onde, diferente dos derrames, tem-se um sistema fechado.

A alta concentração de $\mathrm{Sr}$ e $\mathrm{Rb}$, respectivamente maior que $600 \mathrm{ppm}$ e $400 \mathrm{pmm}$, nas amostras da re-
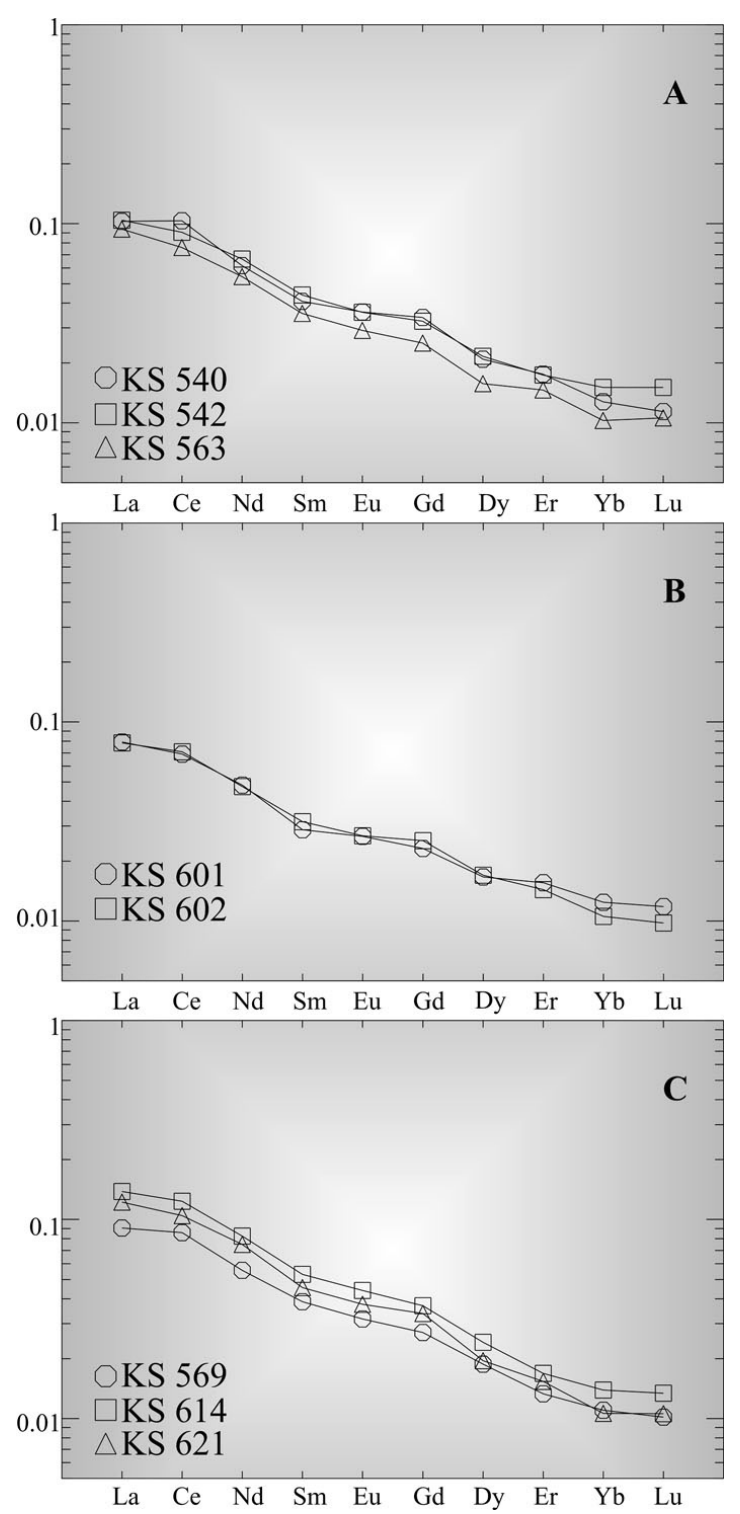

Figura 22 - Padrões de abundância dos elementos terras raras, normalizados em relação ao manto primordial (McDonough \& Sun, 1995), das amostras selecionadas como representativas, com composições para maiores, menores e traços discriminados na tabela 2 . Legenda: A - Amostras do tipo Pitanga; $B-$ Amostras do tipo Paranapanema; $C$ - Amostras do tipo Urubici.

gião de Franca, parte norte, discriminado na figura 21, pode mostrar relação com processos de contaminação crustal, que mascararam as características geoquímicas originais.

Já os diabásios da área em foco apresentam variabilidade química maior distribuindo-se de forma relativamente bem definida. Os diabásios do sill de São Sebastião do Paraíso, localizado também a norte do Rio Sapucaí Mirim, a exemplo dos basaltos provenientes dos derrames observados próximo a esta região, são do tipo Urubici. Por ouro lado, os diabásios provenientes dos sills de Cajuru, Leme e Iracemápolis, localizados 


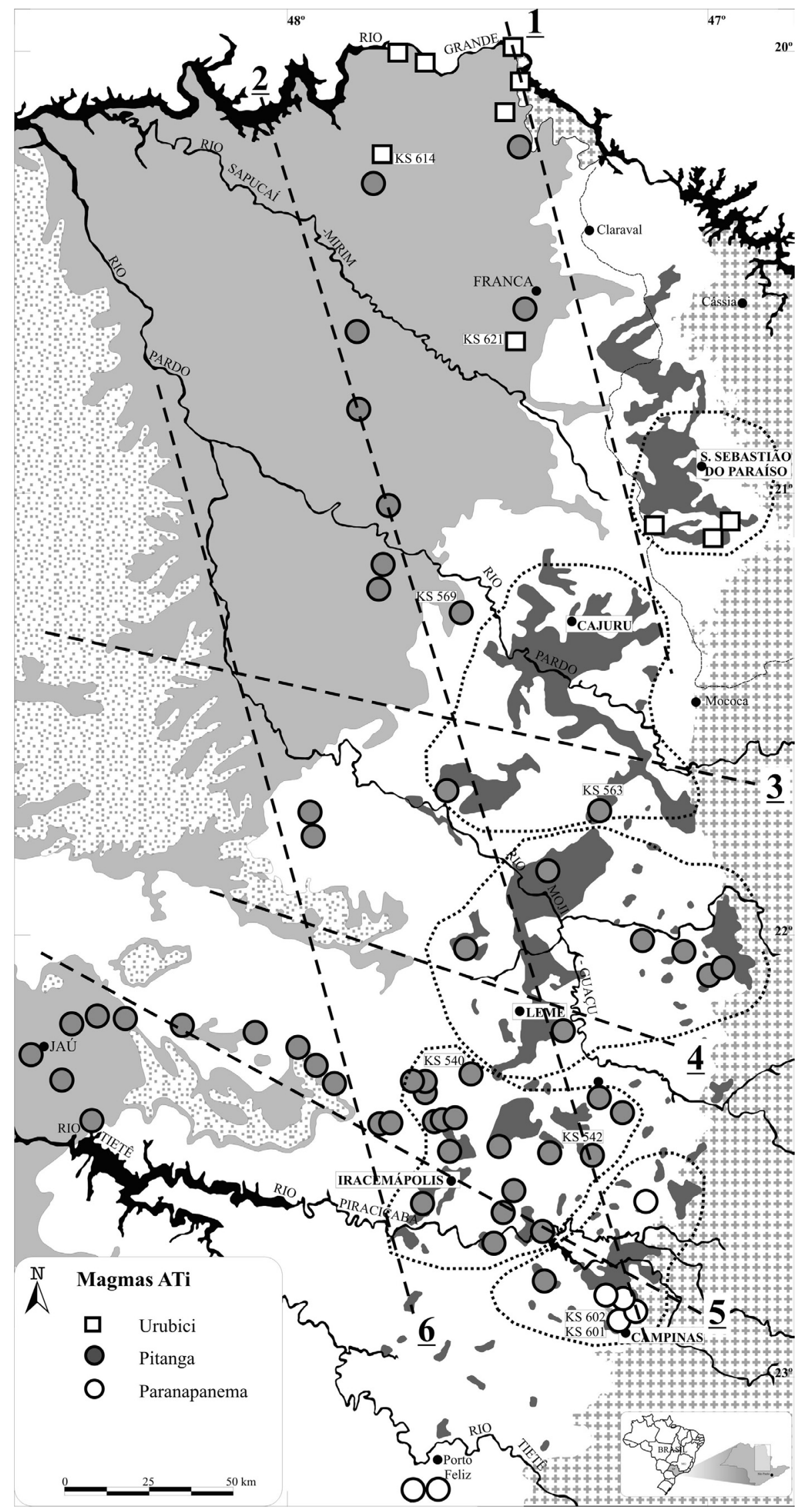

Figura 23 - Mapa Litogeoquimico da área investigada. Mapa Geológico segundo CPRM (2005) e alinhamentos estruturais em NE do Estado de São Paulo segundo Riccomini (1997). Legenda: 1 -Alinhamento Rifaina - São João da Boa Vista; 2 - Alinhamento Ribeirão Preto - Campinas. 
na porção centro-sul da área estudada, apresentam características geoquímicas compatíveis com aquelas do magma Pitanga, enquanto que os diabásios do sill de Campinas, especialmente aqueles coletados ao sul do Rios Tietê e Piracicaba, são do tipo Paranapanema, figura 23.

Essa compartimentação também foi notada através de dados paleomagnéticos onde a região localizada ao norte do Rio Sapucaí Mirim apresenta polaridade normal e ao sul, a polaridade é reversa (Ernesto et al., 1999 e Marques \& Ernesto, 2004), parecendo indicar que estas rochas foram geradas em épocas distintas.
Por fim, parece que os alinhamentos estruturais de direção NW-SE sugeridos pelos lineamentos dos rios Sapucaí Mirim, Tietê e Piracicaba influenciaram a compartimentação destas rochas na área estudada, a exemplo do que ocorre com os alinhamentos de mesma direção, de presença comum na Bacia do Paraná, como os da região do Arco de Ponta Grossa.

Agradecimentos Os autores agradecem a FAPESP (2003/10979-2) e FUNDUNESP (00112/2003-DFP) pelo financiamento da pesquisa.

\section{Referências}

Almeida F.F.M. 1986. Distribuição regional e relações tectônicas do magmatismo pós-Paleozóico no Brasil. Revista Brasileira de Geociências, 16:325-349.

Asmus H.E. \& Baisch P.R. 1983. Geological evolution of the Brazilian continental margin. Episodes, 4:3-9.

Assine M.L., Piranha J.L., Carneiro C.D.R. 2004. Os paleodesertos Pirambóia e Botucatu. In: V.M. Neto, A. Bartorelli, C.D. Carneiro, B.B. de Brito-Neves (eds.) Geologia do Continente Sul-Americano: Evolução da Obra de Fernando Flávio Marques de Almeida. Editora Beca, p. 77-92.

CPRM - Companhia de Pesquisa de Recursos Minerais. 2005. Mapa Geológico do Estado de São Paulo. São Paulo, escala 1:500 000.

Bellieni G., Brotzu P., Comin-Chiaramonti P., Ernesto M., Melfi A.J., Pacca I.G., Piccirilo E.M., Stolva D. 1983. Petrological and Paleomagnetic Data on the Plateau Basalts to Rhyolite sequencies of the Southern Paraná Basin (Brazil). Anais da Academia Brasileira de Ciências, 55:355-383.

Bellieni G., Comin-Chiaramont P., Marques L.S., Martinez L.A., Melfi A.J., Nardy A.J.R., Piccirilo E.M., Stolva D. 1986a. Continental flood Basalts from Central-Western Regionas of the Paraná Plateau (Paraguay and Argentina): Petrology and Petrogenetic Aspects. Neues Jahrbuch Miner. Abh., 154:11-139.

Bellieni G., Comin-Chiaramonti P., Marques L.S., Melfi A.J., Piccirilo E.M., Nardy A.J.R., Roisenberg A. 1984a. High- and low-Ti flood basalts from the Paraná plateou (Brazil): petrology end geochemical aspects bearing on their mantle origin. Neues Jahrbuch Miner. Abh., 150:272-306.

Bellieni G., Comin-Chiaramonti P., Marques L.S., Melfi A.J, Stolfa D. 1984b. Low-pressure evolution of basalt sills from bore-holes in the Paraná Basin, Brazil. Tschermaks Min. Petr. Mitt., 33:25-47.

Bellieni G., Comin-Chiaramonti P., Marques L.S., Melfi A.J., Nardy A.J.R., Papatrechas C., Piccirillo E. M., Roisenberg A. 1986b. Petrogenetic aspects of acid and basaltic lavas from the Paraná plateau (Brazil): geological, mineralogical and petrochemical relationships. Journal of Petrology, 27:915-944.

Ernesto M., Raposo M. I. B., Marques L.S., Renne P.R., Diogo L.A., De Min A. 1999. Paleomagnetism, geochem- istry and ${ }^{40} \mathrm{Ar} /{ }^{39} \mathrm{Ar}$ dating of the North-eastern Paraná magmatic province: tectonic implications. Journal of Geodynamics, 28:321-340.

Gallagher K., Hawkesworth C.J., Mantovani M.S.M. 1994. The denudation history of the onshore continental margin of SE Brazil inferred from apatite fission track data. Journal of Geophysical Research, 99:18117-18145.

Godoy D. F. 2006. Termotectônica por Traços de Fissão em apatitas dos altos estruturais de Pitanga, Pau d'Álho e Jiboia - Centro do Estado de São Paulo. Dissertação de Mestrado, Instituto de Geociências e Ciências Exatas, Universidade Estadual Paulista, 128 p.

Irvine T.N. \& Baraguar W.R.A. 1971. A guide to the chemical classification of the common volcanic rocks. Canadian Journal of Earth Sciences, 8:523-548.

Le Bas M.J., Le Maitre R.W., Streckeisen A., Zannetin B. 1986. A chemical classification of volcanic rocks based on total alkali-silica diagram. Journal of Petrology, 27:745-750.

McDonough W.F. \& Sun S.S. 1995. Composition of the Earth. Chemical Geology, 120:223-253.

Malagutti M.I.A., Bahia O.F., Moreno M.M.T., Nardy A.J.R. 1988. Determinação de elementos terras raras e ítrio em rochas silicáticas por ICPAES com separação em resina trocadora de íons. Geochimica Brasiliensis, 12:75-80.

Mantovani M.S.M., Marques L.S., Souza M.A., Atalla L., Civeta L., Inonocenti F. 1985. Trace Element and Strontium Isotope Constrains of the Origin and Evolution of Paraná Coantinental Flood Basalts of Santa Catarina State (Southern Brazil). Jour. of Petrology, 26:187-209.

Marques L.S. \& Ernesto M. 2004. O Magmatismo Toleítico da Bacia do Paraná. In: V.M. Neto, A. Bartorelli, C.D. Carneiro, B.B. de Brito-Neves (eds.) Geologia do Continente Sul-Americano: Evolução da Obra de Fernando Flávio Marques de Almeida. Editora Beca, p. 245-263.

Marques L.S., Figueiredo A.M.G., Saiki M., Vasconcellos M.B.A.1989. Geoquímica analítica dos elementos terras raras - Aplicação da técnica de análise por ativação neutrônica. In: M.L.L. Formoso, L.V.S. Nardy, L.A. Hartmann (eds.) Geoquímica dos Elementos Terras Raras no Brasil. CPRM/DNPM - SBGq, p. 15-20.

Milani E.J. 2004. Comentários sobre a origem e evolução tectônica da Bacia do Paraná. In: V.M. Neto, A. Bartorelli, C.D. Carneiro, B.B. de Brito-Neves (eds.) Geolo- 
gia do Continente Sul-Americano: Evolução da Obra de Fernando Flávio Marques de Almeida. Editora Beca, p. 265-279.

Nardy A.J.R., Oliveira M.A.F. de; Betancourt R.H.S., Verdugo D.R.H., Machado F.B. 2002. Geologia e estratigrafia da Formação Serra Geral. Rev. Geociências, 21:15-32.

Nardy A.J.R., Enzweiler J., Bahia F ${ }^{\circ}$ O., Oliveira M.A.F., Peneiro M.A.V. 1981. Determinação de Elementos Maiores e Menores em Rochas Silicáticas por Espectometria de Fluorescência de Raios-X: Resultados Preliminares. In: Congresso Brasileiro de Geoquímica, 6, Resumos Expandidos, p 346-348.

Peate D., Hawkesworth C.J., Mantovani M.S.M. 1992. Chemical Stratigraphy of the Paraná Lavas (South America): Classification of Magma Types and their Spatial Distribution. Bulletin of Volcanology, 55:119-139.

Petrini R., Civetta L., Piccirillo E.M., Bellieni G., CominChiaramonti P., Marques L.S., Melfi A.J. 1987. Mantle heterogeneity and crustal contamination the genesis of low-Ti Continental Flood Basalts from the Paraná Plateau (Brazil): Sr-Nd isotope and geochemical evidence. Journal of Petrology, 28:701-726.

Piccirillo E.M. \& Melfi A.J. (eds.) 1988. The Mesozoic Flood Volcanism of the Paraná Basin: Petrogenetic and Geophysical Aspects. São Paulo, IAG-USP, 600p.

Piccirillo E.M., Raposo M.I.B., Melfi A.J., Comin-Chiaramonti P., Bellieni G., Cordani U.G., Kawashita K. 1987. Bimodal fissural volcanic suítes from the Paraná Basin (Brazil): K-Ar age, Sr-isotopes and geochemistry. Geochimica Brasiliensis, 1:53-69.
Piccirillo E.M., Civetta L., Petrini R., Longinelli A., Bellieni G., Comin-Chiaramonti P., Marques L.S., Melfi A.J. 1989. Regional variations within the Paraná flood basalts (southern Brazil): evidence for subcontinental mantle heterogeneity and crustal contamination. Chemical Geology, 75:103-122.

Piccirillo E.M., Comin-Chiaramonti, Melfi A.J., Stolfa D., Bellieni G., Marques L.S., Giaretta A., Nardy A.J.R., Pinese J.P.P., Raposo M.I.B., Roisenberg A. 1988. Petrichemistry of Continental Flood Basalt-Rhyolite Suites and Related Intrusives from the Paraná Basin (Brazil). In: E.M. Piccirillo \& A.J. Melfi (eds.) The Mesozoic Flood Volcanism of the Paraná Basin: Petrogenetic and Geophysical Aspects. São Paulo, Instituto Astronômico e Geofísico - Universidade de São Paulo. p. 107-156.

Renne P.R., Ernesto M., Pacca I.G., Coe R.S., Glen J.M., Prévot M., Perrin M. 1992. The Age of Paraná Flood Volcanism, Rifting of Gondwanaland, and the JurassicCretaceous Boundary. Science, 258:975-979.

Riccomini C. 1997. Arcabouço Estrutural e Aspectos do Tectonismo Gerador e Deformador da Bacia Bauru no Estado de São Paulo. Revista Brasileira de Geociências, 27:153-162.

Zanettin B. 1984. Proposed new chemical classification of volcanic rocks. Episodes, 7:19-20.

Manuscrito AE-046/2006

Recebido em 04 de outubro de 2006 Aceito em 13 de março de 2007 